\title{
Polygamy, the Commodification of Women, and Underdevelopment
}

\author{
Daniel Seligson $^{1 \star(1)}$ and Anne E. C. McCants ${ }^{2}$ \\ ${ }^{1}$ Independent Scholar and ${ }^{2}$ Massachusetts Institute of Technology, 77 Massachusetts Ave, Cambridge, \\ MA 02139, USA \\ *Email: daniel.seligson@gmail.com
}

(Received 15 August 2019; revised 26 May 2020; accepted 4 November 2020; first published online 14 September 2021)

\begin{abstract}
Family systems shape social institutions, yet they are rarely considered in histories of economic development. In this article, we show that a suite of social conventions-such as age gaps at marriage, bride price, sequestration, and discrimination and violence against women-are overrepresented in polygamous societies as compared to monogamous societies. This dichotomy can be explained on the grounds that polygamy produces a chronic scarcity of marriageable females. We argue that this suite, which we call gamos and which we quantify by two different methods, has demonstrably significant consequences for social, institutional, and economic development.
\end{abstract}

Keywords: Family law; marriage; social stratification; economic development; institutions

Man is more powerful in body and mind than woman, and in the savage state he keeps her in a far more abject state of bondage than does the male of any other animal.

Charles Darwin, The Descent of Man

\section{Introduction}

Every human, indeed, every large primate, begins her or his integration into society at birth in the ecological niche defined by its mother, for it is there that we learn, by example, how to interact with others and whom to trust (Hrdy 1999: 383ff). As such, family and household are elemental to any discipline concerned with the social world. Not surprisingly, the household is a critical unit of analysis in and across anthropology, demography, sociology, and family history. In contrast, economics and political science have given it considerably less attention, focusing instead on the individual actor/citizen and their interactions with the marketplace or

(C) The Author(s), 2021. Published by Cambridge University Press on behalf of the Social Science History Association. This is an Open Access article, distributed under the terms of the Creative Commons Attribution licence (http:// creativecommons.org/licenses/by/4.0/), which permits unrestricted re-use, distribution, and reproduction in any medium, provided the original work is properly cited. 
the state. This scholarly divide is exacerbated by methodological differences. For instance, family history, with its concern for the particular experiences of households over the life course, leans toward case studies as is typical of the history discipline. Economic history, however, has moved increasingly into the orbit of economics, where it takes its primary task to be raising broad questions about long-term processes and the generalizable laws that govern them. These differences of both topic and approach limit the transfer of knowledge across the divide.

Where then is the family in economic history? ${ }^{1}$ Douglass C. North, founder of the New Institutional Economics (NIE), argues that "institutions are the rules of the game," and more specifically that institutions are humanly devised constraints that serve to reduce uncertainty and transaction costs, acting thereby to improve economic performance. ${ }^{2}$ The NIE's definition of institutions includes informal constraints, e.g., taboos, culture, and social norms, all of which are propagated from generation to generation through the family, though not exclusively so. Alongside these, the NIE also considers formal constraints, of which constitutions and codified property rights are prime examples. Thus, it might seem that the family is squarely in the analytical framework of the NIE, but that is not the case because the NIE has chosen to focus on formal constraints only. ${ }^{3}$ According to Oliver Williamson, the NIE's rules of the game are the formal constraints of polity, bureaucracy, and judiciary, for example (Williamson 2000: 597). He designated these L2, shorthand for Level 2. Informal constraints, designated L1, are synonymous with socially embedded conventions and are explicitly not the rules of the game. ${ }^{4}$ The NIE has been unsuccessful in incorporating social convention, in which family values or structure might be implicated. North highlights the paradoxically pervasive influence of norms on the long-term performance of economies (North 1991: 111), but neither he nor Williamson, who reiterates the point (Williamson 2000: 596), offers an explanation, nor to our knowledge does anyone else.

\footnotetext{
${ }^{1}$ In neoclassical economics, while the role of family is not altogether absent, it is nonetheless easy to miss, showing up more often at the edges of the discipline than as a key explanans. Gary Becker's A Treatise on the Family (1981) is considered authoritative on this subject by many economists, but historians find in it little that is recognizable. His "family economics" method applies neoclassical concepts to the decision processes that shape family life, such as marriage, fertility, education, or the sexual division of labor. It does not concern itself foremost with how family processes shape the economic behavior of individuals once in the marketplace, nor more importantly how differing family systems contribute to the long-run processes of development that constitute the object of so much work in economic history.

${ }^{2}$ The NIE is not alone in making the claim that factors beyond rational choice are essential to understanding economic behavior. In a landmark paper, sociologist Mark Granovetter wrote of "the extent to which economic action is embedded in structures of social relations" (Granovetter 1985: 481). In the same year, economist Robert Solow wrote that "all narrowly economic activity is embedded in a web of social institutions, customs, beliefs, and attitudes" (Solow 1985: 328). These papers have institutionalized "embeddedness" as a conceptual if not analytic framework for thinking about what underlies neoclassical economics.

${ }^{3}$ Deirdre McCloskey mocks this narrow focus of the NIE, calling it a prescription to "add institutions and stir" (McCloskey 2016: 10).

${ }^{4}$ Williamson eschews the formal/informal distinction in favor of one based on the timescale of their evolution. The rules of the game change over the course of decades or less and socially embedded convention changes over the course of centuries if not longer (Williamson 2000: 597).
} 
Another place the family appears in economic history is in the literature on the impact of gender inequality and the treatment of women in shaping economic outcomes. Yet, the focus of this literature is primarily one about equity rather than family systems per se. In particular the European Marriage Pattern (EMP) has been invoked as a harbinger of both gender equality and modern economic growth (Hajnal 1965; Hartman 2004). Scholars have disputed both the definition of the EMP and the mechanisms by which it might have affected various regions of Europe differently (Carmichael et al. 2016; De Moor \& van Zanden 2010; Dennison \& Ogilvie 2014). However, we believe that the EMP debate, while important locally, has missed the most salient factor characterizing family systems in their global scope, that is, the dichotomy between polygamy and monogamy.

Formally, polygamy may mean either male plural marriage, polygyny, or female plural marriage, polyandry, or even some combination thereof, but in practice, there is very little ambiguity. Polyandry is practiced in societies whose members comprise less than 2 percent of the global population, and only in polygynous societies (Becker 1981: 102; Trevithick 1997). In the Muslim world, which comprises a fifth of the world's population and more than a third of the population in societies where polygamy is practiced, there is no ambiguity. Muslim women have no right to marry more than one man, so polygamy is identical to polygyny. In China, where polygamy was legal until 1950, its Mandarin pictogram 夫多妻 translates to “man bigger than sky with lots of wives." The term polygyny is rarely used outside some academic disciplines, whereas polygamy, conveying the same meaning, is standard usage for economists and political scientists writing for academic and popular journals, for example, Politico and The Economist. It is also the preferred usage of policy makers, for instance at the United Nations, and it is the term of art in the English language press of Kenya, Nigeria, Ghana, and South Africa, to name a few examples. In this article, we use polygamy, polygyny, and male plural marriage synonymously, as does Fenske explicitly (2015: 58) and as do others implicitly.

Monogamy, the root of the EMP, is so overwhelmingly the norm in the West that the aforementioned studies do not even consider its alternative. To many Westerners that alternative is infidelity (Perel 2006). However, infidelity is no more a marriage system than is divorce. The alternative marriage system is polygamy, and we will show that insofar as socioeconomic impact is concerned, male plural marriage, which is synonymous with the term polygamy as used here, bears an outsized influence. Globally, societies that tolerate or promote male plural marriage are more numerous than monogamous ones, and the social dynamics of polygamous households impinge more on their monogamous neighbors than the other way around. On that topic, Laura Betzig's 1986 Despotism and Differential Reproduction was pioneering. Tacitly accepting that polygamy has conferred (over anthropological times scales) and does confer (contemporaneously) differential reproductive success, she argues that autocratic governance and polygamy are inextricably intertwined. More recently, Alean Al-Krenawi (2014) describes an ensemble of adverse effects of polygamy that bear on all members of polygamous households, and Rose McDermott (2018) documents the widespread harm inflicted beyond the polygamous family. Bare Branches, a study of high-sex-ratio societies - which are superficially similar to polygamous ones-illuminates how sexselective infanticide and abortion, and unequal access to resources contribute to crime 
and social instability (Hudson and den Boer 2005). ${ }^{5}$ Finally, Michele Tertilt (2005) observes that bride price, a practice that is all but unique to polygamous societies and consists of a transfer of assets from the groom's family to the bride's father, creates market incentives that elevate fertility and contribute to poverty. Her work stands alone, since that of Becker (1973), for its theorizing on the subject of male plural marriage and economic outcomes.

Though polygamy is very widespread, as we will show in the first of the sections that follow, it is remarkable how little work has quantitatively evaluated polygamy as a factor in shaping social and political institutions or studied its impact on longterm economic development. Our goal in this article is to address this shortcoming. In particular we explore how polygamy gives rise to social conventions, a term we use interchangeably with norms, that are either absent altogether or much diminished in monogamous society; we develop new measures to quantify them; and we use a multivariate causal model to show that polygamy, through the action of its conventions, has profoundly influenced the social, institutional, and economic development of nations. As a measure of that development, we augment the UN Human Development Index (HDI) with an additional component of governance per Amartya Sen's Development as Freedom (2000).

\section{Where Is Polygamy in the World?}

The most comprehensive global survey of contemporary polygamy is Rose McDermott's (2010). Combining assessments of laws, practices, and $w$, a measure of plural marriage prevalence, McDermott codes each of 176 nations on an integer scale between 0 and 4 (see figure 1A). ${ }^{6}$ Though a distinction on the basis of customary or religious law would seem at first glance to have no more or less gravitas than one made on the basis of national law, the histogram in figure $1 \mathrm{~B}$ suggests that the former is weightier. We observe that the distribution of states is bimodal, cleaving along the line of legality in customary or religious law. This separates 4.1 billion people in $93 \mathcal{P}$-states where polygamy is legal under such law from 3.3 billion people in $83 n \mathcal{P}$-states where it is not.

We begin by focusing on polygamy's molding of social convention. Following the lead of philosopher and social theorist David Lewis, we understand convention to be a normative behavior - that is one accompanied by could, would, or should - that is adhered to by almost all members of society (1969). The requirement of near-universal adherence, in conjunction with the fact that human socialization begins in infancy and is well-established by adolescence, suggests that convention may change only on a timescale of generations. That being the case, whatever the convention is today, it is the consequence of events and practices that transpired long ago. While laws_customary, religious, or national-likely reflect convention, contemporary law cannot itself be the source of contemporary convention. The

\footnotetext{
${ }^{5}$ Bare Branches is a univariate study. In as much as high sex ratio societies are both similar to and different from polygamous ones, conclusions drawn from statistical or econometric analysis must include both high sex ratio and polygamy, or risk the consequences of omitted variable bias.

${ }^{6}$ Measured as a fraction, $w$, the number of women in male plural marriages is typically somewhat more than twice the number of men in such marriages.
} 
(A)

\begin{tabular}{|c|c|c|c|c|c|}
\hline Coding & $\mathrm{N}$ & Customary/Religious Law & National Law & $w^{\mathrm{d}}$ & $\mathcal{P} / n \mathcal{P}$ \\
\hline 0 & 79 & Illegal $^{\text {a }}$ & Illegal & $<2^{\mathrm{e}}$ & $n \mathcal{P}$ \\
\hline 1 & 4 & Illegal $^{\mathrm{b}}$ & Illegal & $>2$ & $n \mathcal{P}$ \\
\hline 2 & 20 & Legal $^{\mathrm{c}}$ & Illegal & $<5$ & $\mathcal{P}$ \\
\hline 3 & 56 & Legal & Unenforced & $<25$ & $\mathcal{P}$ \\
\hline 4 & 17 & Legal & Unenforced & $>25$ & $\mathcal{P}$ \\
\hline
\end{tabular}

(B)

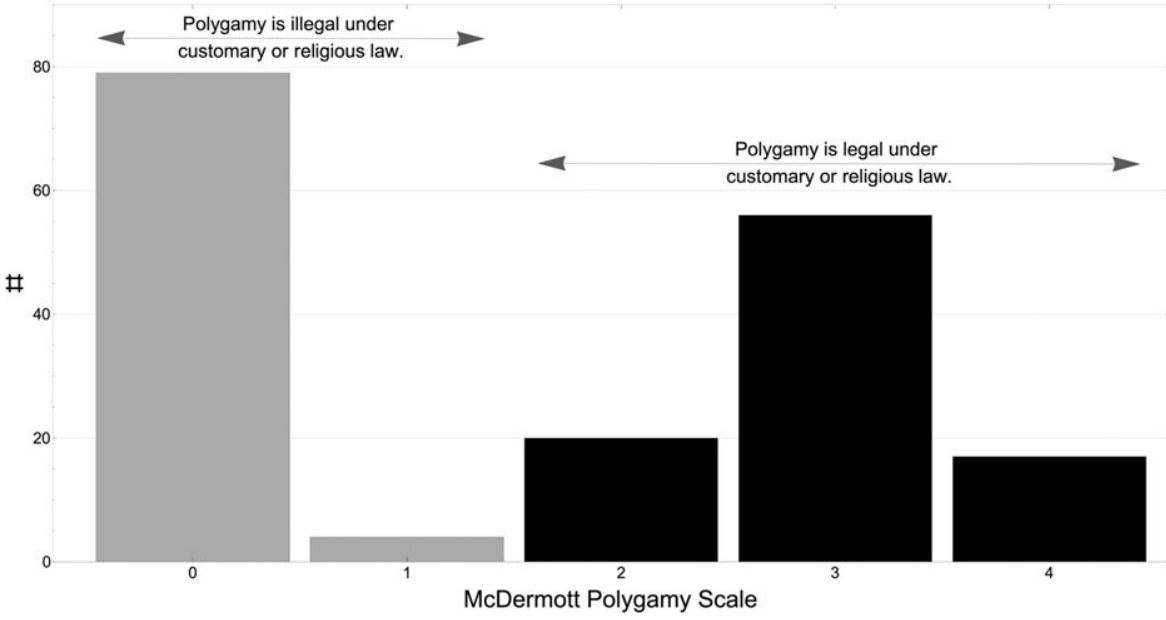

Figure 1. McDermott's polygamy scale: $(A)$ tabulation and (B) histogram. Notes: 1A: (a) Multiple cohabitations: <2 percent; (b) multiple cohabitations: $>2$ percent; (c) only applies to select minorities and/or within enclaves; (d) $w$ is the fraction, specified in percent, of women in plural marriages; and (e) no US agency compiles statistics on covert polygamous marriages. One source has reported, without documentation, that 50,000 to 100,000 Muslims live in polygamous households (Hagerty 2008). Another says, also without documentation, that 50,000 to 100,000 Black Muslims live in polygamous relationships (Al-Krenawi 2014). From these it seems fair to estimate that no more than 0.1 percent of American marriages are polygamous. In figure 1B, the vertical axis label (\#) signifies the number of states in each classification category. The world according to McDermott's coding scheme is evidently bimodal, cleaving along the line of customary and religious law's view of polygamy.

twentieth century's roiling social upheavals were often accompanied by new or unfamiliar legal systems. We can expect, therefore, that contemporary law is out of step with convention in some states. As a predictor of contemporary convention, the $\mathcal{P} / n \mathcal{P}$ classification based on contemporary customary and religious law is likely to be inferior to such a classification made on the basis of customary and religious law in 1900. This warrants some changes to the $\mathcal{P} / n \mathcal{P}$ classification we have just made on the basis of contemporary law per McDermott's Polygyny Scale. We describe these changes in the following five paragraphs.

Polygamy was legal under customary law as recently as 1999 in Azerbaijan, 1990 in Laos, 2015 in Myanmar, and 1956 in Tunisia. Though they are classified as $n \mathcal{P}$ in the McDermott coding, we designate them $\mathcal{P}$. China is reportedly free of polygamy 
today though it was prevalent there from the ancient past until the time of Mao (Lee and Feng 2001; Zurndorfer 2016). Consequently, China is $\mathcal{P}$, and so too is Mongolia, which only won its independence from China in 1921.

On the other hand, McDermott classifies Singapore as 2, and therefore $\mathcal{P}$ in our system. But it was a small British colony in 1900 whose nearly hundredfold population growth in the intervening years qualifies it, in our view, as a new country whose norms are not typical of other $\mathcal{P}$-states. For this reason, we classify Singapore as $n \mathcal{P}$.

We must classify the Muslim-majority Balkans (Albania and Kosovo) as $\mathcal{P}$, and also Bosnia and Macedonia where Muslims comprise about 40 percent of the population. ${ }^{7}$ Finally, Fiji is a McDermott 0 , though its long tradition of Chiefly Polygamy, irrespective of contemporary law, makes it $\mathcal{P}$ (Luker 2015).

In the Muslim-majority Russian Republic of Chechnya, civil law prohibiting polygamy gives way to customary law permitting it (Tetrault-Farber 2015). ${ }^{8}$ In McDermott's system, Russia is a 2 and therefore $\mathcal{P}$. But Russia is historically Orthodox, and Christendom has been monogamous since its earliest days under Roman rule where polygamy was at first not-normative and then later a crime (Witte 2015: 104-14). The overwhelmingly dominant convention in Russia is thus monogamy. We classify it as $n \mathcal{P}$.

In the Americas, Belize, Suriname, and Haiti are the only states that have laws, customary or civil, that permit or at least tolerate polygamy, and are thus $\mathcal{P}$. By contrast, Guyana is a McDermott 0, but UNICEF reports that the plural marriage fraction there is 4 percent (2014). ${ }^{9}$ Accordingly, Guyana belongs among the $\mathcal{P}$-states. ${ }^{10}$

By this revised coding, approximately 5.5 billion people live under the influence of $\mathcal{P}$ and 2.0 billion live without such influence in $n \mathcal{P}$. The global distribution of our revised $\mathcal{P} / n \mathcal{P}$ is shown in map 1 , and a complete list is provided in the appendix. ${ }^{11}$

\section{The Social Conventions of Polygamous Society}

Polygamy is an asymmetric marriage contract-formal or informal, secular or religious, legal or illegal — that deprives the bride of the right of further marriage while preserving that right for the groom. Even in societies where it is permitted, generally fewer than one in three married men are polygamous, and more typically, fewer than one in ten. ${ }^{12}$ Though seemingly rare, the mere possibility of such

\footnotetext{
${ }^{7}$ Recently in Albania, 6 percent of married men were in plural marriages (Gruber 2002).

${ }^{8}$ Given the fact that polygamy is a virtue in Islam (Elbedour et al. 2002), it is probable that what holds in Chechnya also holds in the Russian republics of Ingushetia, Dagestan, Karachay-Cherkessia, KabardinoBalkaria, Tatarstan, and Bashkortostan, in each of which the Muslim population exceeds 38 percent.

${ }^{9}$ Plural marriage fraction, which we will denote $p$, is distinct from and less than $w$, the fraction of women in plural marriages. Generally speaking, one needs an additional piece of information, the number of wives per plural marriage, to compute $p$ from $w$ or vice versa.

${ }^{10}$ Supporting this, the linguist Walter Edwards has reported on the adoption in Guyana of West African marriage traditions, specifically bride price, which are otherwise unique to polygamous society (1982).

${ }^{11}$ In addition to the states in McDermott's classification, we add Samoa as $\mathcal{P}$ and Antigua and Barbuda, Grenada, and Seychelles as $n \mathcal{P}$.

${ }^{12}$ This is consistent with McDermott's findings, wherein the female plural marriage fraction-which is typically somewhat more than twice the male plural marriage fraction $-\mathcal{P}$ was less than 25 percent in 76 of $93 \mathcal{P}$-states.
} 


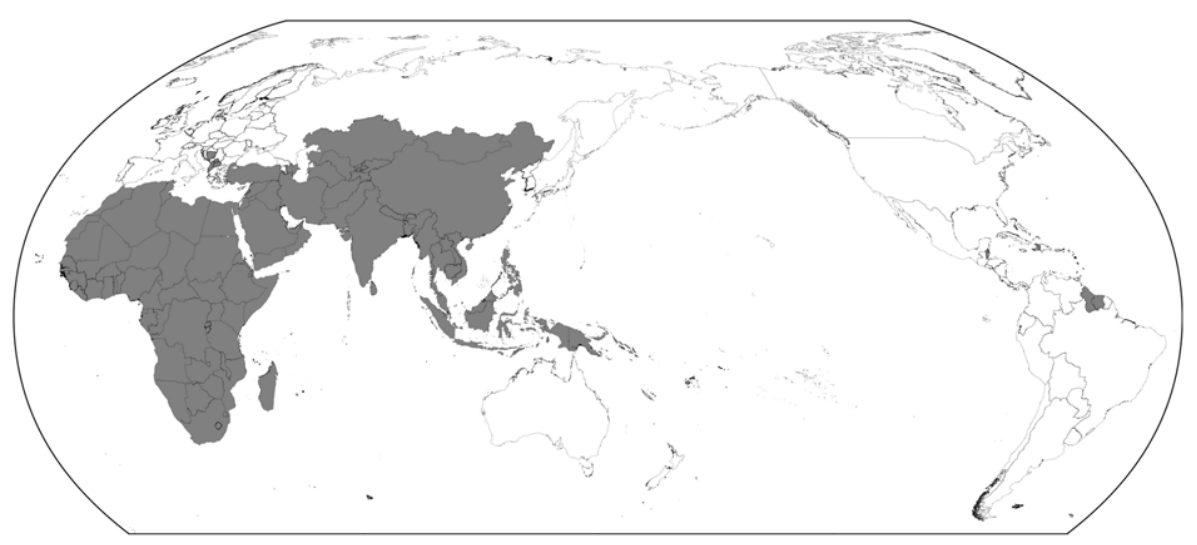

Map 1. World map of $102 \mathcal{P}$-states (in gray) and $75 n \mathcal{P}$-states (in white).

asymmetric two-party contracts requires the tacit approval of most members of the community and supporting institutions that extend far beyond the sphere of the parties. Social conventions consistent with those contracts and their institutions will affect almost everyone within the sphere of permission. The driving mechanisms of polygamous convention and their consequences are the subject of this section.

In the 1710 edition of Transactions of the Royal Society, the world's first scientific journal, Dr. John Arbuthnot (1710: 186-90) reported on the relative birth rates of girls and boys, finding them approximately equal, a conclusion supported by contemporary data as shown in figure 2. He also noted that, "where Males and Females are in equal number, if one man takes twenty wives, nineteen must live in celibacy, which is repugnant to the design of Nature." He would have had no firsthand experience of polygamy in European society, though he would have known polygamy was common in Africa, and he might also have known something about its prevalence in the Near East, as did his contemporary Montesquieu (2008 [1721]), or in the Far East, as had been reported by Marco Polo in the thirteenth century (1958: Book 1, Chapter 52). He may be forgiven, then, his inference about celibacy, which is strictly correct only if marriage is restricted to parties of the same age. But his demography is sound and it bears heavily on polygamy. So long as men may take more than one wife, and women may not do the same, and so long as the male-to-female sex ratio at the age of puberty is not much less than unity-a condition that is satisfied everywhere-then polygamy creates a chronic scarcity of marriageable females.

Being that scarcity is at the root of economic behavior, the economist's imagination is not tested by the proposition that women in polygamous society are traded like any other commodity. Nor is it tested by the proposition that the chronic scarcity influences economic outcomes in polygamous society relative to monogamous societies that do not face that particular scarcity. Whether that differential is large or small, or positive or negative remains to be determined. In this section we elucidate how a chronic scarcity of marriageable females molds social convention and promotes the commodification of all women. 
(A)

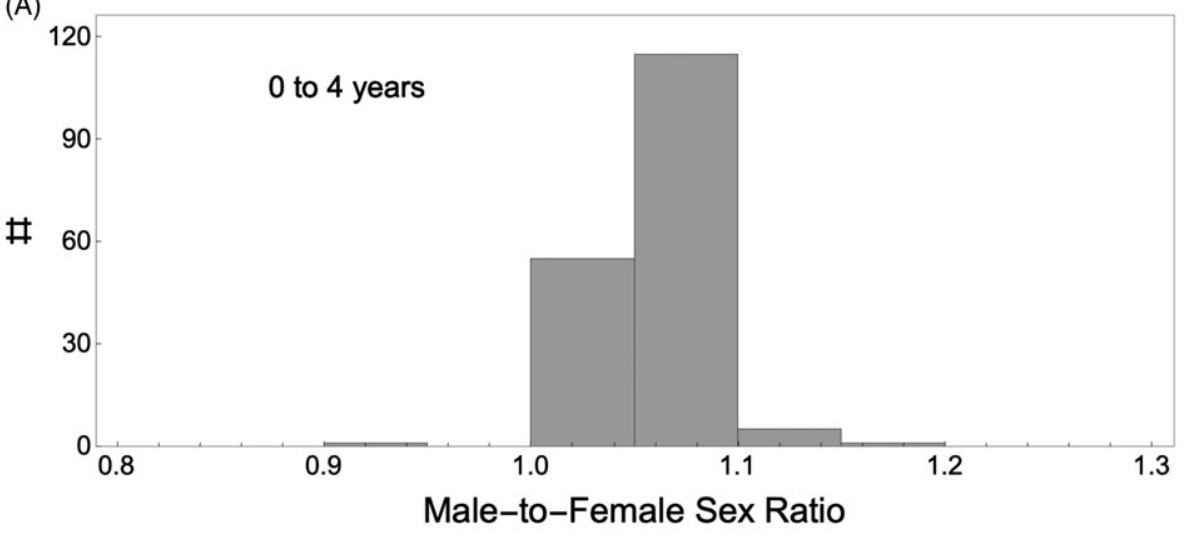

(B)

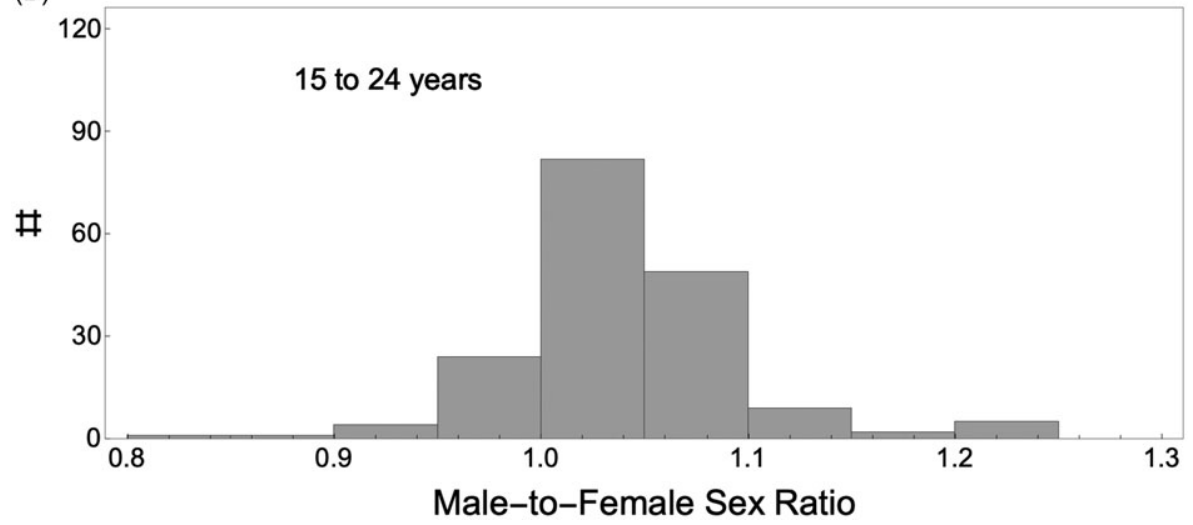

Figure 2. Male-to-female sex ratios for 177 nations. Notes: (A) Sex ratios in the first four years of life and (B) sex ratios in the first decade after puberty. Means and medians for both age groups are about 1.05. Population weighted means are larger by about 0.03 owing to sex ratios greater than 1.12 in China and India. Five states-Qatar, UAE, Bahrain, Maldives, and Kuwait-have sex ratios after puberty exceeding 1.2 , a fact that may be attributed to a preference for males in their immigrant workforces.

When a community is struck by famine or drought, historical experience shows that those with access to scarce essentials often hoard them and those who don't have access either maraud for them or suffer. To the extent possible or desirable, state and private institutions distribute the necessities from stockpiles to ameliorate the suffering and to protect the interests of the politically powerful. If scarcity and suffering mount, the afflicted grow more restive, flee, or even die. Where redistribution fails to quell civil disturbances, state and private militias may do so. But such scarcities often originate in the weather, and like the weather they pass, first coming and then going. As with recollections of a great blizzard, the transient scarcity fades, and it does so without engendering materially permanent behavioral change for almost all members of the group, which is requisite for our definition of convention.

Chronic scarcity is altogether different. It does not come and go like the weather. It comes and stays on a timescale of centuries, like climate. Within a few 
generations, no living person can recall the world before the scarcity took hold. ${ }^{13}$ If the scarcity does not pose an existential threat, or if alternatives can be found to alleviate the most dire of its consequences, then conventions adjust to the new normal and the old cultural system passes into legend.

Marriageable women are not like food or water; a man in search of a wife will not die in weeks for lack of a mate. However, the reproductive instinct is intrinsic to all life, leading us to expect that the logic of the market will apply where marriageable women are scarce, as they are wherever polygamy is permitted. In the following, we identify 11 different conventions that we hypothesize will be overrepresented in polygamous society. Because other factors independent of polygamy may give rise to these same conventions in nonpolygamous society, we do not expect that these conventions are necessarily absent there. We do, however, expect that they will be less prevalent there.

First, where marriageable women are a scarce commodity, we expect that they will be more highly valued in the marriage market, and that families with daughters will approve their marriage only for a price. Unlike dowry, which is a transfer of assets from the bride's family to the married couple, bride price is a transfer of assets from the groom or the groom's family to the bride's family. Typically, these accrue to her father. Valerie Hudson (2016) has developed an 11-point grading system for the full range of at-marriage wealth transfers: 0 signifies that neither dowry nor bride price is common; 1 to 5 signifies a range of dowry conventions; and 6 to 10 signifies a range of bride price conventions. By her design, circumstances for women are less favorable as the index value increases. We divide her sample of 173 states into groups according to the $\mathcal{P} / n \mathcal{P}$ classification. By visual inspection, the distributions of wealth transfer conventions within $\mathcal{P}$ and $n \mathcal{P}$, figures $3 \mathrm{~A}$ and $3 \mathrm{~B}$, respectively, are so dissimilar as to be distinct. Furthermore, bride price, we observe, is a practice all but unique to polygamous society. ${ }^{14}$

As a quantitative diagnostic of similarity between two distributions, economists have long employed the Kolmogorov-Smirnov or KS test (Dagum 1980). It hinges on the observation that two distributions are similar only if their cumulative distribution functions (CDF) differ by at most a small amount, $\delta$. The KS test generates an estimate of the probability that two distributions are the same. That probability, $p_{K S}$, is exponential in the term $-\mathcal{N} \delta^{2}$, where $\mathcal{N}$ is of the order of the number of elements in the smaller of the two distributions. $p_{K S}$ is therefore nonnegligible only if $\delta \leq 1 / \sqrt{ } \mathcal{N}$. In the case at hand, $\mathcal{N} \cong 70$, so $p_{K S}$ is nonnegligible only if $\delta \leq 0.12$. The CDFs of $\mathcal{P}$ and $n \mathcal{P}$ distributions of at-marriage wealth transfers are shown in figure $3 \mathrm{C}$. The corresponding $\delta \cong 0.9$, so $p_{K S}$ is vanishingly small. We conclude,

\footnotetext{
${ }^{13}$ From the requirement that almost all members of a group adhere to a convention, and from the fact that such behavioral norms are generally learned in the first few years of life, we may infer that conventions change on a timescale of multiple generations, a timescale far longer than one we associate with a temporary shortage.

${ }^{14}$ That bride price is all but unique to polygamy is evidence that the scarcity mechanism, absent in $n \mathcal{P}$, is responsible for it. We do not assert, nor do we find, that other forms of wealth transfer at marriage are impossible in $\mathcal{P}$. We note further that Botticini and Siow show that, contrary to the theorizing of Gary Becker, bride price does not emerge in response to the disappearance of dowry. Rather it exists independently, and is strongly associated, they say, with the practice of polygyny, especially in Africa (Botticini and Siow 2003: 1385, 1390).
} 
(A)

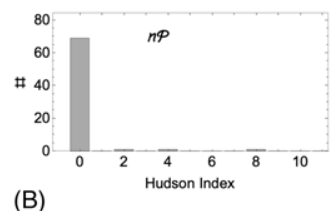

(B)

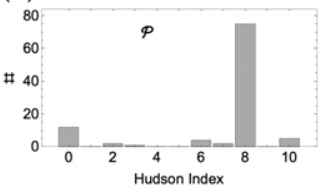

(C)

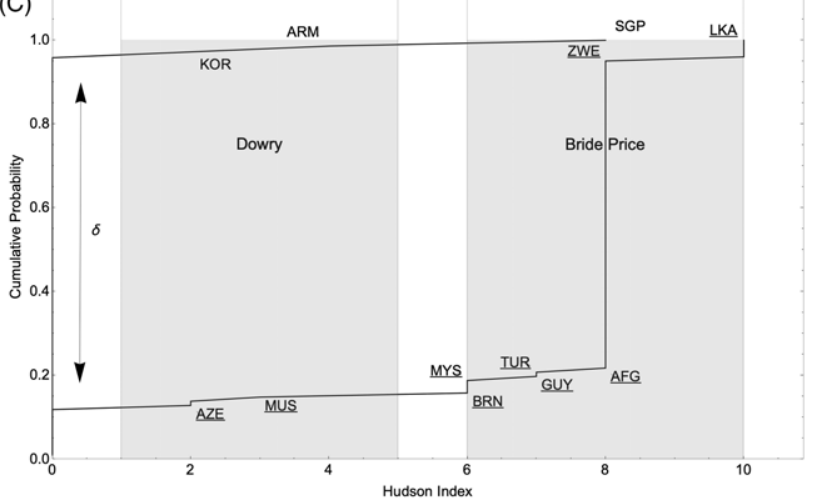

Figure 3. Hudson's index of wealth transfers at marriage. Notes: (A) The distribution of wealth transfers at marriage per Hudson's index in $73 n \mathcal{P}$ states. (B) The distribution of wealth transfers at marriage per Hudson's index in $100 \mathcal{P}$ states. (C) The cumulative distribution functions of the $\mathcal{P}$ and $n \mathcal{P}$ distributions. The maximum difference, $\delta$, of these is approximately 0.9 , generating a vanishingly small $p_{k s}$, from which we conclude that the distributions are distinct, as expected.

therefore, that the $\mathcal{P} / n \mathcal{P}$ dichotomy gives rise, in the case of wealth transfers at marriage, to distinctly different conventions, as we hypothesized.

We claim, if contentiously, that polygamy causes, or is one of the causes of the convention we call bride price, or $\mathcal{P} \rightarrow B$ in the notation of causal inference theory (Pearl and McKenzie 2018: 128ff). By this we mean that (1) there exists a mechanism by which $\mathcal{P}$ effects $B$; (2) $\mathcal{P}$ is highly correlated with $B$; (3) $\mathcal{P}$ precedes $B$; and (4) there is no confounding factor $Z$ that induces changes to both $\mathcal{P}$ and $B$. Having already demonstrated (1) and (2), we proceed to investigate (3) and (4).

In The Histories of Herodotus (fifth century $\mathrm{BCE}$ ) polygamy was present throughout Eurasia and Africa, though it was absent in Athens and possibly other Greek city-states. This absence is consistent with Diane Hughes's assessment of the absence of bride price in the same sources (1978: 262-63). Polygamy was present, too, among the Greeks in The Iliad, as well as documented in eighth-century BCE China (Golden 2002: 49). Thus, polygamy was present everywhere in the historical record at least 2,700 years before the present. ${ }^{15}$ If a nonpolygamous society existed before that time, it left no record and its impact on marriage structure was transient. Society emerged in the presence of preexisting polygamy. ${ }^{16}$ It follows that the polygamy-born scarcity of marriageable females was a fact on the ground for emergent society to manage, just as it had to manage scarcities of food, water, and shelter. The solutions to those management challenges are social conventions,

\footnotetext{
${ }^{15}$ Ancient history tells us little about polygamy in the Americas in that time, but supporting our claim is the fact that many of its indigenous societies were polygamous at the time of conquest and some remain so today (Chagnon et al. 2017; Pearsall 2019).

${ }^{16}$ Sexual size dimorphism in Homo sapiens confirms the fact that we inherited polygamy from our Miocene ancestors among the great apes, all of whose extant descendants are polygamous (Plavcan 2012: S413). Whether polygamy was a constant or whether it waned and then waxed in the Holocene, we cannot know.
} 
Table 1. Eleven social conventions and descriptive statistics of their distributions in $\mathcal{P}$ and $n \mathcal{P}$

\begin{tabular}{|c|c|c|c|c|c|}
\hline \multirow[b]{2}{*}{ \# } & \multirow[b]{2}{*}{ Convention } & \multirow[b]{2}{*}{ Units } & \multicolumn{2}{|c|}{ Means $(\sigma)$} & \multirow[b]{2}{*}{$p_{K S}$} \\
\hline & & & $n \mathscr{P}$ & $\mathscr{P}$ & \\
\hline 1 & Bride Price & 0 to 10 & $0.2(1.1)$ & $6.9(2.8)$ & $3 \times 10^{-31}$ \\
\hline 2 & Birthrate & per yr per $1 \mathrm{k}$ & $12.8(3.8)$ & $25.6(9.2)$ & $7 \times 10^{-18}$ \\
\hline 3 & Age Gap at First Marriage & years & $3.0(0.7)$ & $4.5(1.7)$ & $3 \times 10^{-09}$ \\
\hline 4 & Patrilocality & 0 to 2 & $0.4(0.7)$ & $1.6(0.6)$ & $5 \times 10^{-17}$ \\
\hline 5 & Property Rights & 0 to 4 & $0.9(0.5)$ & $2.3(1.0)$ & $6 \times 10^{-20}$ \\
\hline 6 & Intermingling & 0 to 4 & $1.1(0.5)$ & $2.2(0.8)$ & $3 \times 10^{-22}$ \\
\hline 7 & Capital Punishment & $0 / 1$ & $0.3(0.5)$ & $0.8(0.4)$ & $4 \times 10^{-11}$ \\
\hline 8 & Physical Security & 0 to 4 & $2.7(0.9)$ & $3.6(0.5)$ & $5 \times 10^{-09}$ \\
\hline 9 & Female Genital M/C & $\%$ & $0(0)$ & $17(30)$ & $8 \times 10^{-14}$ \\
\hline 10 & Differential Education & years & $0.0(0.1)$ & $0.2(0.2)$ & $2 \times 10^{-11}$ \\
\hline 11 & Freedom Index & 0 to 60 & $13(13)$ & $35(13)$ & $3 \times 10^{-16}$ \\
\hline
\end{tabular}

Note: Data tables and their sources are provided in the supplementary appendix.

bride price being one example. The temporal or chronological primacy of $\mathcal{P}$ relative to all convention rules out the existence of a conventional confounder $Z$ that causes $B$. Regarding the existence of a natural confounder, that is, one born of climate or geography, the latter is ruled out because geography is a constant over the Holocene. We rule out climate as a confounder because polygamy was everywhere, irrespective of climate, by the earliest evidence.

The evidence of mechanism, correlation, and chronology, and the absence of evidence of confounders, all point to polygamy being the cause of bride price. ${ }^{17}$ Variations on these arguments apply for the other 10 conventions described in the following text. ${ }^{18}$ Table 1 summarizes the descriptive statistics of the 11 conventions we discuss in this article. We refer to these by name or by line item, for example \# 1 in lieu of bride price.

Just as the market translates the scarcity of marriageable females into the custom of bride price, the same scarcity will, we expect, drive up birthrates and increase the age gap at first marriage as well. The former increases the supply of a valuable commodity and the latter is a form of product substitution, from same-age mates to ever younger girls. ${ }^{19}$ Tertilt asks how it is possible that more than one in three marriages are polygynous given that the sex ratios in most countries do not deviate much from one, and

\footnotetext{
${ }^{17}$ To employ the nomenclature of Hedström and Swedberg, these are the "social mechanisms that produce [the] observed relationships between explanands and explanandum" (Hedström and Swedberg 1996: 281).

${ }^{18} \mathrm{No}$ argument of this kind can be made about the EMP. The characteristics of EMP states are distinctly modern, and an argument in defense of their causal nature must comprehend endogeneities as well as covariates.

${ }^{19}$ Elevated birthrate does, of course, produce males as well as females, but as the matrimonial bride price belongs to the father of the bride, every newborn girl is an asset on his balance sheet. Every newborn boy is just another surplus male, which surplus is not his problem to solve.
} 
then explains that the resolution lies in "extremely high spousal age gaps coupled with high population growth" (Tertilt 2005: 1346). Both practices bear economic costs as well. Tertilt further argues that the practice of buying wives and selling daughters in sub-Saharan Africa is explicitly market driven. Though locally and immediately optimal, it has longer-term negative consequences for economic development. She estimates that banning polygamy could decrease fertility by 40 percent, increase savings by 70 percent, and increase output per capita by 170 percent (Tertilt 2005: 1343) ${ }^{20}$

The mechanism driving the age gap at marriage has three elements. First, when confronted by scarcity in the marriage market, some men will resort to marrying a prepubescent girl. This may be understood as a form of product substitution in a thin market. Second, as it is in the financial interest of the bride's father to encourage such a marriage, he does. Third, because bride price is a financial barrier, a man must delay marriage until such time as he has amassed the necessary capital to overcome it. These factors work together to increase the age gap at first marriage.

Consistent with Tertilt's work on sub-Saharan Africa, lines \#2 and \#3 in Table 1 bear out the predictions for both birthrates and marital age gaps. Birthrates are nearly twice as high in $\mathcal{P}$ as in $n \mathcal{P}$-states, and age gaps at marriage are greater in $\mathcal{P}$ by 1.6 years, exceeding by more than 50 percent the age gap in $n \mathcal{P} .{ }^{21} \mathrm{We}$ recognize that the relationship between social customs and economic behavior is complex, and that the mechanisms identified here are not the only ones at work. However, for our purposes, the mechanisms previously described correctly predict the observed sign of the $\mathcal{P} / n \mathcal{P}$ differentials, and that is all that is necessary for our argument.

Polygamy's bride price culture informs us that women are highly valued in $\mathcal{P}$ but that their value accrues to older males. ${ }^{22} \mathrm{We}$ can expect, therefore, that other social

\footnotetext{
${ }^{20}$ Banning polygamy is more easily said than done. Carmeliza Rosário observed that in Mozambique, banning polygamy "plays against some of the women the law is intended to protect; particularly since the law does not eliminate per se the mechanisms of the patriarchal system" (2008:1). Because the law works against those women, they are not motivated to observe it. This is an example of norms superseding laws, or what Douglass North would have described as informal institutions superseding formal ones.

${ }^{21}$ The age gap differential between $\mathcal{P}$ and $n \mathcal{P}$ is greater than reported here. The data shown is singulate mean age gap at first marriage, and thus does not take into account the effect of plural marriage. Using that singulate data in conjunction with actual plural marriage prevalence, we estimate that the plural marriage age gap differential is greater than the singulate value by 0.9 years, a very large difference given that the standard deviation of age gap in $n \mathcal{P}$ is 0.7 . Tertilt reports an even larger gap of 6.8 years in her study of 28 countries, all from sub-Saharan Africa with the exception of Bangladesh (2005: 1367). It is interesting to note that in some rare instances, age gap at marriage may fall rather than grow as a response to genderimbalanced scarcity. In a study of marital behavior in France following World War I, Abramitzky et al. (2011) find that the relative scarcity of males increased the likelihood that men would marry, lowered the ages at which they did so, and thereby lowered the age gap between nuptial partners. But such a mechanism must be transient, not chronic, except in societies that are perpetually in a state of war, and no nation today qualifies as such.

${ }^{22}$ Given the value placed on women in polygamous states, it may seem odd that they are commodified, but it seems less odd when we look at the parallels with slavery. Slaves were valuable, being the source of energy that powered multiple industries, and yet slaves were commodified. Had they not been commodified, their labor value would have accrued to their own selves and not to their owners. However, the anthropologist Emmanuel Todd opines-in a little read but important book about the origins of ideology in family structure- that the universality of men withholding power from women is more rigidly observed than the nearly universal strictures against incest (Todd 1985: 22).
} 
conventions will reinforce the male grip on power (a not unreasonable understanding of patriarchy) and that such conventions, like the three just identified, will be differentially represented in $\mathcal{P}$ and $n \mathcal{P}$. First consider patrilocality, wherein the bride relocates to the home of her new husband's family. Hrdy writes that "female autonomy depends on the availability of support from her kin" (1999: 102). The convention of patrilocality decouples a young bride from that support and subordinates her to the groom and his family. This is especially so given the notably early age at which women marry in $\mathcal{P}$, and even more so in higher-order plural marriages where the age gap may amount to decades. Line item \#4 in Table 1 makes evident that patrilocality predominates in $\mathcal{P}$.

Second, property and landownership laws and practice in $\mathcal{P}$-states discriminate against women to a demonstrably greater extent than in $n \mathcal{P}$-states, as affirmed by \#5 in Table 1 . Property rights are recognized by most scholars as a critical component of economic development. Thus the two-tier system puts women at a further disadvantage in society. Polygamy-born scarcity increases the value of women, and discriminatory property rights enables men to retain for themselves the value of those women they possess, whether "possess" has figurative or literal meaning.

In a related but somewhat different vein, it is a well-observed fact that scarce commodities are hoarded and that they must be safeguarded against marauding and decay. In his classic work on the economics of shortage among socialist firms, Janos Kornai argues that chronic scarcity leads to hoarding and "an almostinsatiable demand" for the scarce commodity (Kornai 1980: 102). The demand for women in $\mathcal{P}$ is not merely almost insatiable, it is actually insatiable because women are both the scarce commodity and the means of its production through their fertility.

Given that polygamous societies have too few women, and given the logistical challenges of raiding at a distance, we hypothesize that polygamous societies raid near-neighbors to acquire females. Tribalism is a source of otherization that justifies warring behavior. Raiding has two other ends: (1) fungible material booty serves to improve a man's position in his community and consequently his marriage prospects; and (2) for every man who dies raiding, the odds of reproductive success increase for the survivors. Work by evolutionary biologists Luke Glowacki and Richard Wrangham (2015) supports this expectation. Similarly, Robert Tignor's 1972 study of violence among the Maasai in Kenya and Tanzania emphasizes the centrality of raiding to wealth-building, noting that it is a prerequisite to marriage and admission to the circle of elders. Also, the surge in raiding that is associated with the start of the Viking Age was one consequence of polygyny and concubinage in the Late Iron Age (Raffield et al. 2017: 316). Wealth is inseparable from marriage, and both are a means to enfranchisement because it is only the elders who hold authority in community decision making. Anthropologists and ethnographers know these patterns well. ${ }^{23}$

No less so than any other scarce commodity, a man's wives, daughters, sisters, and mothers are safe from predation only when isolated from marauders. Men

\footnotetext{
${ }^{23}$ Hartung et al. (1982) reports that among 1,170 societies documented in George Murdock's monumental Ethnographic Atlas, polygyny is practiced in at least 860 .
} 
cannot be trusted, at least insofar as women are concerned. ${ }^{24}$ It is predictably prudent, therefore, that men will isolate their assets behind walls, and that when necessity dictates that these assets mingle in public, men will act to ensure their safety by shielding them from view beneath formless dress or behind veils, and will demand that they be accompanied by trusted guardians. Line item \#6 in Table 1 confirms that a woman's right to intermingle in public is substantially different in $\mathcal{P}$ and $n \mathcal{P}$, being relatively abridged in the former, as predicted.

Stratification of males and the accompanying rites-of-passage rituals are well documented in polygamous tribal society, for example, the Maasai (Osborn 1996: 114). ${ }^{25}$ When tribal society is subsumed into larger civil society where intertribal raiding is prohibited by formal law, the scarcity of marriageable females that motivated raiding remains in place so long as polygamy is practiced. The disenfranchised male may seek his enfranchisement by contravening civil society's strictures against violence when he perceives that violence is the sole available means to that end. That such males are largely in the 19 to 34 age group that is infamously responsible for the vast majority of violent crime only makes such rebellion more likely (Farrington 1986). ${ }^{26}$ Chronic scarcity is thus suggestive of chronic violence. The latter could be countered in two ways. One, the sequestration of women, overrepresented in $\mathcal{P}$, addresses the specific threat of kidnap, rape, or murder. The second is, we predict, harsh justice. ${ }^{27}$

Consider the death penalty as an indicator of a harsh judicial system. There are, per Amnesty International (2012), 75 states that impose harsh justice in this sense, and 98 that do not. Amnesty catalogs formal issuances of the state, but not informally issued death sentences such as honor killing and femicide carried out by the dishonored family. ${ }^{28}$ Of Amnesty's 98 abolitionist states, honor killings and

\footnotetext{
${ }^{24}$ In principle, such marauders could be male or female, but owing to their larger size and greater strength, and to female sequestration, the marauders are, for the most part, male. A proverb of the traditionally polygamous Bedouins runs as follows: Me against my brother, me and my brother against our cousin, us against the clan, the clan against the tribe, and the tribe against the world. Karen Armstrong writes of this society, "outside the tribe, obligation ceased" (Armstrong 1993: 58). Thus, raiding other tribes is permitted, consistent with what one would expect of a polygamous society. Within the tribe, trust in all things, says the proverb, is calibrated to familial distance.

${ }^{25}$ One stratum, the so-called junior males, is comprised of (mostly young) adults without wives and the other stratum is comprised of married elders.

${ }^{26} \mathrm{By}$ this logic, married men may be expected to be less violent than their unmarried peers. This is found to be the case in one study which reports that "states of marriage causally inhibit crime over the life course" (Sampson et al. 2006).

${ }^{27}$ The economist and legal scholar John Donohue uses the term "implicit crime rate" to illuminate the dynamic balancing of criminality and enforcement (Donohue 2017: 1307). He notes that the 2014 murder rate in the United States, 44 per million, was lower than at any time since 1957, in part as a consequence of policies that increased incarcerations to the highest level the world has ever seen. The murder rate that would have been observed without exceptional incarcerations and other suppressive forces, what he calls the "implicit murder rate," is much higher. Thus, a nation's criminal justice system is a reflection of implicit as well as real or observed criminality within its borders.

${ }^{28}$ Amnesty International reports that over the period 2007 to 2011, there were about 2,900 executions or death sentences per annum. The World Health Organization reported that the prevalence of honor killing is not less than 5,000 per year (Garcia-Moreno et al. 2012). That the object of honor violence is usually a woman and that the practice has something to do with polygamy may be understood from the following: sequestration is convention in $\mathcal{P}$. It is expected, therefore, that every family will sequester its women and that
} 
femicides are "either ignored or generally accepted" in 26 of them (Womanstats 2020). Employing a definition of capital punishment that includes both formal and informal channels, we find that 80 of $101 \mathcal{P}$-states and 21 of $72 n \mathcal{P}$-states practice harsh justice. In this binary accounting, capital punishment is dominant in $\mathcal{P}$ as we hypothesized (see \#7 in Table 1).

Honor killing and femicide are the terminal point on a gray scale of violence against women. Checks on such violence in general are, we expect, few in $\mathcal{P}$, where the male's sense of ownership of the women in his household is reinforced by patrilocality, discriminatory property rights, and the other factors discussed thus far. This is borne out in \#8, which employs a 5-point scale to characterize the physical security of women (Womanstats 2020). On the low end, in states graded 0 , an ideal achieved nowhere on Earth, there are laws against domestic violence, rape, and marital rape, these laws are enforced, and there are no taboos against reporting them. On the high end, in states graded 4, there are weak, rarely enforced laws against rape, and all other sex is presumed to be consensual. An example of a weak law is one that confines the definition of rape to sex with a girl under the age of 12 .

We now turn to female genital mutilation or cutting, fgm/c, arguing that this practice restricts a woman's freedom of movement by virtue of intimidation, thereby reinforcing male power. As such, it is yet another sequestration convention, and we expect to find it overexpressed in $\mathcal{P} .{ }^{29}$ Convergent evolution might well yield identical conventions from independent sources, and indeed the United Nations, the World Health Organization, the World Bank, the International Center for Research on Women, Human Rights Watch, and others are at pains to find what unifies the practice of fgm/c across Islamic, Christian, and animist communities; in Jewish communities in Ethiopia (Belmaker 2012); in areas as geographically separated as West Africa and the Philippines; in countries both in and out of the tropics; and in countries above and below global means of income. We identify confirmed $\mathrm{fgm} / \mathrm{c}$ states $(\mathrm{N}=38)$ as those meeting either of the following two criteria: UNICEF reports greater than 1 percent prevalence of fgm/c among women of ages 15 to 49, or McDermott reports a prevalence of greater than 25 percent (McDermott 2007; UNICEF 2016). One hundred percent of so-confirmed fgm/c states are $\mathcal{P}$. We identify a second or provisional category $(\mathrm{N}=11)$ based on reporting by the Orchid Project or credible news sources (Orchid Project 2020). Of these 11 states, 100 percent are also in $\mathcal{P}$. See $\# 9$ in Table 1 . By reason of parsimony, the 100 percent congruence of $\mathcal{P}$ and fgm/c favors polygamy (over convergent evolution) as its single dominant cause.

As noted, fgm/c is in decline, and some states that practiced it in the twentieth century have eliminated it in the twenty-first century. If a multitude of those former

a violation of sequestration is taboo. Honor killing is consistent with the definition of taboo, which calls for murder or excommunication of the violator (Freud 1950 [1913]).

${ }^{29}$ Various organizations aim to eradicate fgm/c, and it is in decline, though at least one organization, African Women Are Free to Choose (AWAFC) aims to preserve it on the grounds that only cultural relativism separates those who hold it in high regard from those who condemn it (Ahmadu 2016). The AWAFC argument reinforces rather than undermines our argument that fgm/c is a matter of convention because, per Lewis (1969), the origins of convention are lost in time. To wit, neither AWAFC nor its cofounder, anthropologist Fuambai Sia Ahmadu, who is also Minister of Gender and Social Welfare in $\mathcal{P}$ state Sierra Leone, offers any cogent theory of fgm/c's origins. 
fgm/c states are $n \mathcal{P}$, then that would at least dent, and possibly invalidate, the argument we have made. Though there is no comprehensive study of this matter, we know of no evidence that would suggest that there was even one such case. By contrast, the aforementioned data suggests that some $\mathcal{P}$ states have cut back on their fgm/c practices between 2007 and today, with the Democratic Republic of Congo, Jordan, Kazakhstan, and Sri Lanka, having materially eradicated it. The fact that Israel, an $n \mathcal{P}$-state, was an fgm/c-state as recently as 1995 confirms rather than disproves the rule, as the subpopulation within Israel that practiced $\mathrm{fgm} / \mathrm{c}$ was a Bedouin one in which the plural fraction of all marriages is between 20 percent and 36 percent (Abu Rabia 2011).

Consider now the educational opportunities for girls and young women in $\mathcal{P}$. Fathers in $\mathcal{P}$ will (by convention) collect a bride price for their daughters upon marriage, leading us to expect that the investments in daughters are calculated to maximize financial return. Given that (by convention) girls in $\mathcal{P}$ marry relatively early and bear relatively many children, we hypothesize that they receive relatively little education. To test this, we assess the difference in male and female education measured in years, normalize that difference to male education in years, and compare the distributions in $\mathcal{P}$ and $n \mathcal{P} .{ }^{30}$ Line item \#10 of Table 1 informs us that the distributions are well separated, confirming this hypothesis.

The $11^{\text {th }}$ and final convention we examine is antidemocratic or authoritarian governance. The relationship between marriage law and democracy has a history as long as that of democracy. Classicists Susan Lape (2002) and Walter Scheidel (2009) emphasize that aspects of marriage and inheritance law in Solon's sixthcentury BCE reforms were decisive in the establishment of Athenian democracy. Specifically, the reforms denied inheritance to children of all but the first wife in plural marriages. Noble families that had used plural marriage to concentrate wealth and power were thus denied that mechanism of accumulation. Furthermore, the reforms expanded enfranchisement by linking it to income rather than wealth, thereby favoring the commercial classes at the expense of the nobility. ${ }^{31}$ By the time of the Persian War a century later, the evidence suggests that the city-states had left polygamy behind. Herodotus makes no mention of it among either Athenians or Spartans. ${ }^{32}$ Emphasizing the importance of this transition, Scheidel writes, "Greco-Roman emphasis on 'Socially Imposed Universal Monogamy' deserves pride of place in a world history of monogamy that has yet to be written" (Scheidel 2009: 289).

Despotism is the ultimate in disenfranchisement because it is a system of governance in which only the voice of the autocrat matters. The linkage between disenfranchisement and polygamy is well documented by Betzig (1986). It is

\footnotetext{
${ }^{30}$ By this measure, 0.2 means that boys receive, on average, 20 percent more schooling than girls.

${ }^{31}$ We are grateful to Thomas Martin (private conversation February 15, 2019) who noted that nobility rules on the strength of the privileges it dispenses. The nobility of seventh- and sixth-century BCE Greece was weak in the aftermath of the great wealth- and culture-destroying calamity that took down Mycenaean civilization in or around $1100 \mathrm{BCE}$. Their weakness left them few privileges to dispense and opened the door to these reforms.

${ }^{32} \mathrm{His}$ silence cannot be because he was blind to polygamy, for in his descriptions of Asians and Africans, polygamy is a commonplace, with one example being the numerous wives Darius took upon his ascension to the Achaemenid throne in 522 BCE.
} 
therefore reasonable to expect that democratic impulses toward greater enfranchisement will be suppressed in a polygamous society. Compounding this is the tendency in $\mathcal{P}$ toward violence as a response to scarcity, a tendency that we also expect is more readily countered by autocratic than democratic regimes. ${ }^{33}$

Through the lens of our $\mathcal{P} / n \mathcal{P}$ binary, we look at two independently gathered though highly correlated $(r=0.94)$ measures of democratic institutions: one an annual ranking from The Economist and the other from Freedom House (both 2016). In both cases, the $\mathcal{P}$ and $n \mathcal{P}$ distributions are well separated, supporting the hypothesis that authoritarian governance is overrepresented in $\mathcal{P}$. We report the results from Freedom House, because of its greater global coverage, in \#11. These 11 indicators of convention form the basis of the analysis that follows.

\section{Gamos: A Unified Measure of Polygamous Conventions}

It is a fact that polygamy generates a scarcity of marriageable females, and it is our hypothesis that this scarcity gives rise to normative behaviors or conventions that contribute in turn to social and economic outcomes. The 11 distinct indicators we review in the preceding text are indicative of those dichotomous social outcomes. The descriptions of the 11 behavioral conventions serve to illuminate their scope, but for the purposes of modeling we seek a more compact representation of the collective effect.

Each of the conventions follows the same pattern of separation into distinct $\mathcal{P}$ and $n \mathcal{P}$ distributions, and they are highly correlated as well. ${ }^{34}$ Yet, across different societies the individual conventions are manifest to different extents, so no single one of them stands out as the natural or obvious representative for them all. Together they constitute a suite, a set that is incomplete without all its elements. Principal components analysis (PCA) affords us a means to achieve the compact representation of 11 conventions as a single variable.

Returning to the 11 conventions in Table 1, PCA tells us that the first principal component explains 55 percent of the variance of the full suite. This one component is a good, compact representation for quantitative analysis. We will call it gamos owing to its origin in behaviors linked to marriage patterns, and we denote it $g_{S}$, where the subscript signifies that we obtained this measure from the suite. In figure 4 , we show that the CDFs of the $\mathcal{P}$ and $n \mathcal{P}$ distributions of $g_{S}$ are well separated, as we expect. The vanishingly small $p_{K S}=3 \times 10^{-29}$ confirms that they are distinct.

The behaviors assayed by $g_{S}$ originate in polygamy, though no measure of polygamy is in the data sets that comprise it. ${ }^{35}$ It is, therefore, an indirect measure of the phenomenon that we seek to evaluate. As such, polygamy may not be the only source of those conventions. Were we to deploy $g_{S}$ in the modeling of the final

\footnotetext{
${ }^{33} \mathrm{Hudson}$ and den Boer claim that "high-sex-ratio societies are governable only by authoritarian regimes capable of suppressing violence at home" (Hudson and den Boer 2005: 202). While supportive of our argument owing to some similarities between high-sex-ratio societies and $\mathcal{P}$, no such claim can be validated by the univariate methods those scholars employ.

${ }^{34}$ The median value of the 55 correlations of the 11 different behaviors is $0.50(\sigma=0.12)$.

${ }^{35}$ Robert Merton (1967) would have called these behaviors middle-range conventions.
} 


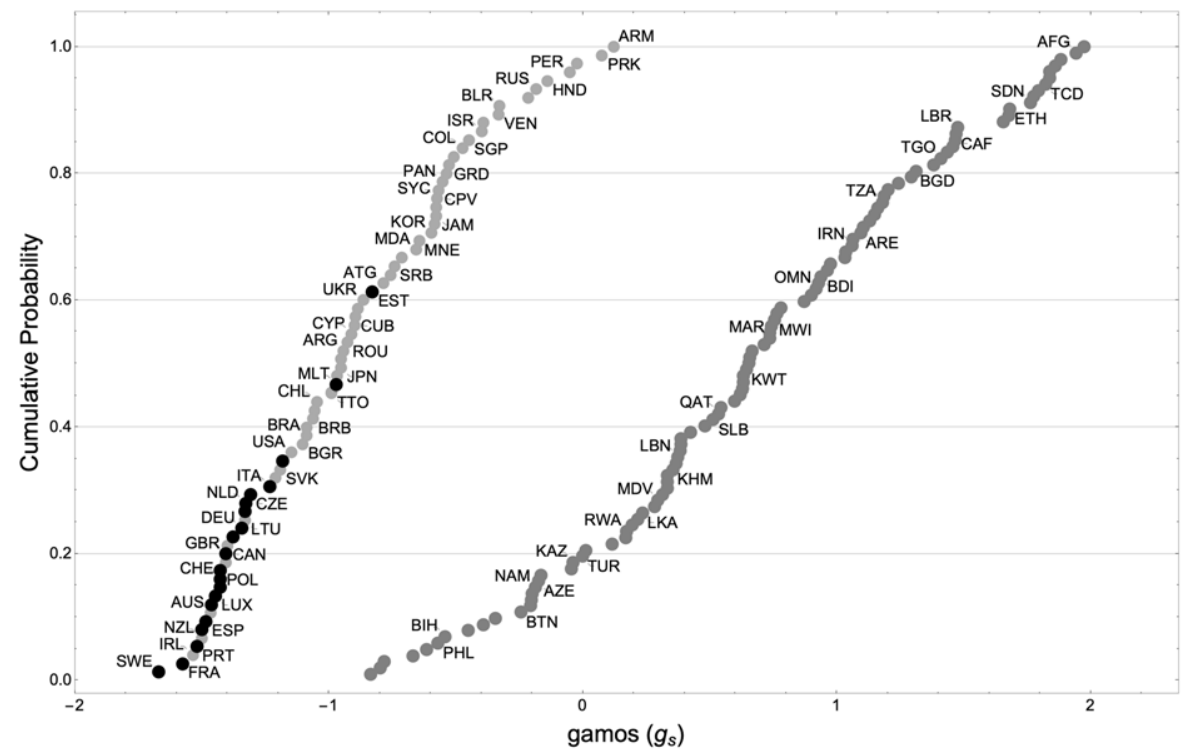

Figure 4. The cumulative distribution functions of $\mathcal{P}$ (to the right) and $n \mathcal{P}$ (to the left) distributions of $g_{s}$. Notes: Within the $n \mathcal{P}$ distribution, we identify members of the EMP (black) and non-EMP (gray) subgroups. Though those two subgroups are themselves distinct, the distinction is modest compared to that between $\mathcal{P}$ and $n \mathcal{P}$ as a whole.

section, we would risk conflating the influence of polygamy with the influence of other, unknown factors. To address this risk, we seek an additional, direct measure of polygamy to serve as a micro-level confirmatory indicator of gamos. The $\mathcal{P} / n \mathcal{P}$ binary is one candidate, as evidenced by the very high correlation $(r=0.85)$ of $\mathcal{P} / n \mathcal{P}$ and $g_{S}$, but we seek a gray scale rather than a binary measure. We will devote the remainder of this section to the construction of such a scale, one we will denote $g$.

Consider the prevalence of polygamy-defined as the male plural marriage fraction-as a candidate for this micro-level measure. It seems plausible that as the prevalence grows, the depth of the scarcity will grow, and the behaviors that follow from that scarcity will be more, rather than less distinct when compared to monogamous society. In the preceding section, we made the $\mathcal{P} / n \mathcal{P}$ binary classification on the basis of customary or religious law in 1900 because contemporary convention may be out of step with contemporary law. Here, by the same logic, we select the opening of the twentieth century as the time frame for our estimate of prevalence. We know that $g_{S}$ is a good measure of gamos, contemporary convention. If $g$ and $g_{S}$ are highly correlated, as we have every reason to expect based on the high degree of correlation between $\mathcal{P} / n \mathcal{P}$ and $g_{S}$, then nineteenth-century prevalence is also a good measure of gamos.

Polygamy and culture are intimately intertwined, and so are culture and geography. The geospatial correlations of polygamy are evident in map 1. Having examined global, regional, and local assays of prevalence, we assert that seven cultural and/or regional traditions provide a sound basis for estimating $g$ almost everywhere. 
Table 2. Regional and or cultural traditions, nominal prevalences of plural marriage fraction c. 1900, and exemplary states

\begin{tabular}{lcl}
\hline Tradition & Prevalence, $\boldsymbol{g}(\%)$ & Exemplar \\
\hline African (low) & 10 & Namibia \\
\hline African (mid) & 15 & Angola \\
\hline African (high) & 22.5 & Kenya \\
\hline Islamic & 10 & Pakistan \\
\hline Near Eastern & 10 & Syria \\
\hline Asian & 6.7 & Nepal \\
\hline Chinese & 6.7 & China \\
\hline Pacific Islander & 22.5 & Papua New Guinea \\
\hline Western & 0 & Spain \\
\hline
\end{tabular}

These are African (within which there are three subcategories), Chinese, Near Eastern, Islamic, Asian (exclusive of China, the Near East, and Islam), Pacific Islander, and Western. ${ }^{36}$ For each of these we posit a prevalence, $g$, whose standard error is $g / 6$. Our assignments, separated by $g / 2$, are thus separated by about three standard errors. We justify this method in the following paragraphs and summarize the assignments in Table 2.

The distribution of female plural marriage prevalences in twentieth-century Africa cluster in three groups. According to Fenske (2015), their nominal values are 30 percent, 45 percent, and 60 percent at mid-century, falling to about half that by its close. In another study of mid-century tropical Africa, predominantly Africa (high) in our system, William Brass et al. report a male plural fraction of 23.7 percent $(\sigma=8.0$ percent, $\mathrm{N}=12$ ) (Brass et al. 1968: 214). These findings, which may appear contradictory, are in fact consistent because female plural fraction is always somewhat greater than twice male plural fraction. From these data we posit that polygamy in early-twentieth-century Africa was typified by low, mid, and high prevalences of 10 percent, 15 percent, and 22.5 percent.

Islam is a world religion whose sectarian and regional differences are vast. Though the prevalence of polygamy among Muslims is highly variable, it does not defy categorization. Tertilt's (2005) estimate of prevalence in Bangladesh is 11 percent. Among Bedouins in the Negev, contemporary prevalence is about 30-35 percent, having increased by 10 percent over the past decade (Al-Krenawi 2014). Chamie's (1986) study of latter twentieth-century polygamy in 13 Arab countries yields a value of 4.6 percent $(\sigma=2.4$ percent, $\mathrm{N}=22)$. If the long-term

\footnotetext{
${ }^{36}$ This categorization is not unlike that described by the World Values Survey Cultural Map, with the main difference being that researchers Ronald Inglehart and Christian Welzel (2017) lump Africa and Islam into one zone whereas we separate them into four, each with its own prevalence, and they subdivide what we call Western (having a single prevalence) into six separate zones.
} 
decline seen by Fenske is mirrored in these Arab countries, then the prevalence in 1900 was, on average, 9 percent. Being the case that polygamous marriages are often not civil marriages and thus not recorded, it is fair to assume that actual polygamy is more prevalent than the civil data shows. In our model, we assign 10 percent to the prevalence of polygamy across Islam, a value that does not stretch credulity.

Islam emerged among the Bedouins in the Hejaz on the western edge of the Arabian Peninsula. Polygamy was the custom among Bedouins, and had been so for millennia among others in the region (Quran 4:3; Genesis 29). It is not unreasonable to suppose that the prevalence of polygamy throughout the Near East was typified by the prevalence among Muslims who codified it. Thus, we assign 10 percent to the Near East tradition.

The traditions we call Asian derive from Buddhist, Hindu, and other cultures across Central and South Asia and, from there, east to Indonesia. ${ }^{37}$ Wendy Doniger's important work on the Hindus notes that polygyny "was the rule, and men could have several spouses throughout most of Hindu history" (Doniger 2009: 296). Indeed, the absence of polygamy in India's labor-intensive agricultural communities would be anomalous, per Becker's theory of the family (1973). Census data from the 1960s and 1970s shows that the bigamy rate among upper-class Hindus was 5.8 percent (Unisa and Mundu 2011) and somewhat higher among Buddhists and other smaller ethnic groups (Dayal 2001). Allowing for the likely possibility that polygamy among upper classes is higher than among the lower ones, we assign $g=6.7$ percent to Asia, exclusive of China, the Near East, Islam, and Russia.

Polygamy in China before communism was a mix of formal marriages and concubinage, both of which would have contributed to a scarcity of marriageable females. Mark Elvin suggests that the daughter of a thirteenth- or fourteenthcentury tenant-serf could become a servant-girl, a wife, or a concubine, and we presume he means a concubine to the landlord (Elvin 1973: 71). In eighteenth- and nineteenth-century Liaoning Province in the north and Taiwan in the south, polygamy rates exclusive of concubinage were less than 2 percent, whereas in the uppermost reaches of the social hierarchy, prevalences exceeded 33 percent, also exclusive of concubinage (Lee and Feng 2001: 76). We have argued, in harmony with Tertilt, that elevated birth rates go hand in hand with prevalence, in order that the scarcity of marriageable females be slaked (2005). Max Roser's study of fertility in 1950 places China squarely among nations whose prevalence was 6.7 percent by our accounting (Roser 2020). Though the data are sparse, we infer from them a value of 6.7 percent for the male plural fraction in China at the turn of the twentieth century, putting it at the low end of our system, and too low in the opinion of some sinologists.

Migrations, isolation, and small tribal chiefdoms in the Solomon Islands, Papua New Guinea, Samoa, and Fiji are consonant with polygamy on a high-African scale (Luker 2015). We assign $g=22.5$ percent for the Pacific Island tradition. Owing to early missionization of Fiji and Samoa, we judge that polygamy was lower in those two systems by 1900, and accordingly, we assign them values of $g=15$ percent.

\footnotetext{
${ }^{37}$ Though Russia straddles the West and Asia, it obeys the logic of the former because it inherited the $g=0$ prescriptive monogamy of the West (Witte 2015) from Byzantine missionaries in the ninth century.
} 


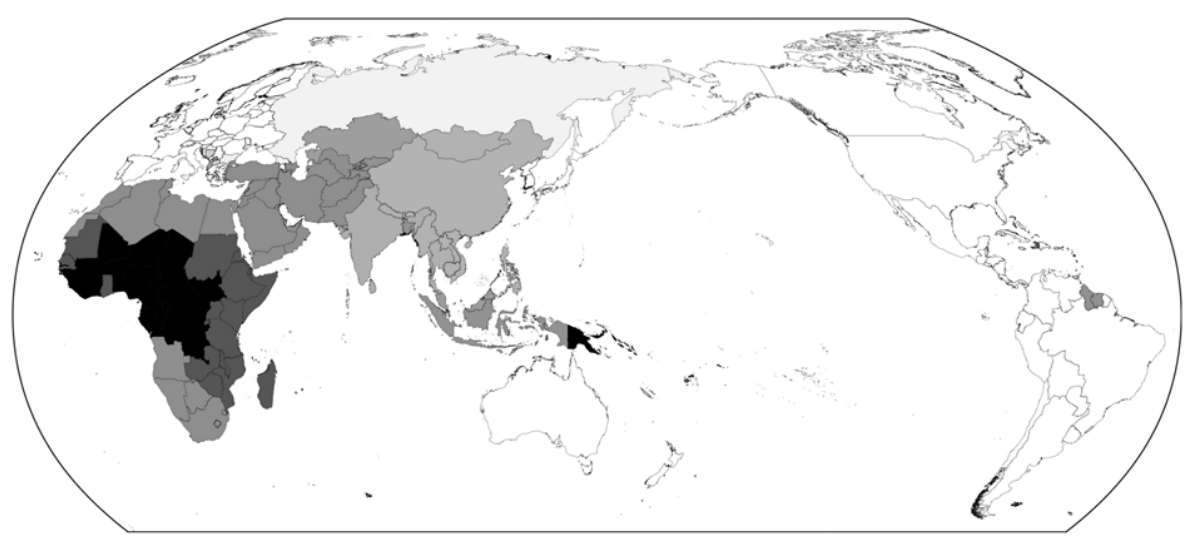

Map 2. A micromeasure of gamos, g, mapped for 177 states. Note: The scale is such that deepest grays correspond to 22.5 percent prevalence in 1900.

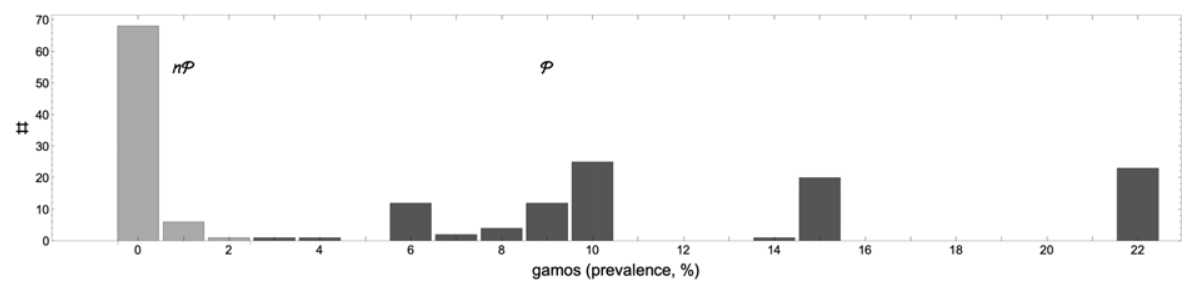

Figure 5. Distribution of prevalence of polygamous marriage in 1900.

The Western marriage model is $n \mathcal{P}$, so we assign $g=0$ for the Western tradition. However, Haiti is in the West, yet a McDermott 3 and thus $\mathcal{P}$. In the appendix we account for this with a refinement of the coarse characterization just described. Therein we apply the refinement to other states as necessary. We illustrate the refined $g$ in map 2 . Just as it is with $g_{S}$, the $\mathcal{P} / n \mathcal{P}$ distinction is manifest as a bimodality in $g$ (see figure 5). We note further that the correlation between the two measures $g_{S}$ and $g$ is 0.83 , though they draw on different data and are developed using very different methodologies. This reaffirms our conviction that contemporary convention $\left(g_{S}\right)$ is a result of longstanding polygamous practice as proxied by $g$, male plural marriage fraction in 1900.

Where in this picture are the Mormons, whose late-nineteenth-century polygamy is a subject of interest? Nowhere, for three reasons. First, our unit polity is a sovereign nation, and united as Mormons may seem to some, they are not now nor have ever been a sovereign nation. Second, as to their impact on the sovereign United States, Mormons reached peak polygamy in 1890 when they formally abandoned it. The population of Utah was about 0.3 percent of the US total. If one-third of all Mormon marriages were polygamous, then it's fair to say that the prevalence in the United States was about 0.1 percent, far below the level that divides $\mathcal{P}$ and 
$n \mathcal{P}$. Finally, the development of convention takes centuries, so the conventions we describe would not have had time to bud, much less reach full flower in the 50-year course of Mormon polygamous history. Nevertheless, the scarcity of marriageable females is evident in contemporary polygamous Mormon compounds, as is the stratification of males by elder and junior rank, the familial social disruption that follows de facto disenfranchisement, the aggravation of age difference at marriage, and the harsh authoritarianism that is necessary to hold the fractious factions together.

\section{A Model of Development That Incorporates Polygamous Convention}

The question at the heart of this article is "where is the family in economic history?" We have developed a theory of how polygamy shapes social convention, and we have quantified polygamous convention at the national level in a measure we call gamos. We aim, ultimately, to quantify polygamy's contribution to macroscopic outcomes such as those broadly encompassed by the term development. In the service of that aim, we will deploy gamos in a causal, multivariate, cross-sectional, global model of development in which the nation is the unit polity, but first we must define our measure of development.

Development, like beauty, is in the eye of the beholder. To an economist, development is the expansion of goods and services. To the King of Bhutan, development is happiness. To an actuary, life expectancy. To Socrates, education. To Amartya Sen, not to mention Franklin Roosevelt, Max Weber, Thomas Jefferson, Adam Smith, Alexis de Tocqueville, and many others, some degree of good governance is an essential feature of prosperity and therefore of development.

The United Nations' definition of development is embodied in their Human Development Index, HDI, a synthesis of highly correlated measures of income, life expectancy, and education, and it has two cardinal virtues that distinguish it from the economist's choice, GDP. First, GDP is unsuited for cross-sectional analysis. This is made plain by the fact that the average of 2006 to 2015 per capita GDPs of the Czech Republic, Equatorial Guinea, Estonia, and Slovakia are approximately equal (World Bank 2020b), a result that is, in our view, at odds with experience. As seen through the lens of HDI, however, the Czech Republic, Estonia, and Slovakia remain peers, while Equatorial Guinea is the peer of Ghana. This does square with experience, though the per capita GDPs of the latter two countries differ by a factor of 12. HDI thus obviates GDPs failings, or many of them.

The second virtue of HDI is that, with few exceptions, a nation's place in the global distribution of HDI, by which we mean its z-score in that distribution, is stable or persistent on a timescale measured in centuries. In work published elsewhere, we find that the correlation of the distribution of HDI at the present moment, to itself at an earlier moment, decays exponentially with a time constant of 626 years (Seligson and McCants 2021). ${ }^{38}$ Alternatively, we may say that the distribution decorrelates at a rate of about 15 percent per century. Either way, this is evidence of a remarkable persistence. In consequence of this persistence, one may be

\footnotetext{
${ }^{38}$ The source of the persistence lies in r-Theory, a dynamical systems theory of the coevolution of institutions and economic performance that is fully described in Seligson and McCants (2021).
} 
confident that models of the $\mathrm{z}$-scored distribution are not sensitive to multidecadal changes of social or economic conditions, and one may rule out, as explanans, those putative sources of development that change on a timescale of decades. Very specifically, the observed persistence rules out the formal institutions favored by the NIE, Williamson's L2, the very institutions that are said to be the rules of the game.

Though HDI incorporates the actuarial and Socratic interests of life expectancy and education, and is superior to GDP as a measure of development, it does not incorporate the interests of political science, that is, governance. To that end, we augment HDI with the World Bank's six Worldwide Governance Indicators (World Bank, WGI, 2018). These indicators are measures of formal institutions, for example judiciaries and administrative bureaucracies, and thus this formulation puts formal institutions where they belong, on the output side and not on the input side of causation. ${ }^{39}$ We denote the new measure $\mu$ and we call it development. ${ }^{40}$ Map 3 illustrates the global distribution of $\mu$ and its large geospatial correlations. Figure 6 illustrates (A) the high correlation of HDI and $\mu(r=0.93)$, and (B) the well-separated distributions of $\mu$ in $\mathcal{P}$ and $n \mathcal{P}$.

Like the distribution of HDI, the distribution of $\mu$ is persistent on long timescales, permitting us to model $\mu$ as a superposition of (mostly) very slowly changing sources of development. We write this as Eq. (1), where $x_{i}^{j}$ denotes the value of the $i^{\text {th }}$ source in the $j^{\text {th }}$ nation, $c_{i}$ is the coefficient expressing the $i^{\text {th }}$ source's contribution to development, and $e^{j}$ is the residual, whose origin may lie in measurement error, stochasticity, or a flaw of model design. The $c_{i}$ are estimated by the ordinary method of least squares on a data set comprised of 177 nations.

$$
\mu^{j}=\sum_{i=0}^{n} c_{i} x_{i}^{j}+e^{j}
$$

If the NIE's favored L2 institutions are not, by reason of persistence, suitable for inclusion among the list of development's candidate sources $x_{i}$, what sources may we include? As already noted, $\mu$ is manifestly geospatially correlated. The likelihood that this arises from a superposition of geospatially uncorrelated sources seems to us low, so $\mu$ 's geospatial correlations convey the message that its sources also have strong geospatial correlations. We may read, then, a list of candidate sources directly from the gross features of map 3, as Dell, Jones, and Olken did when they observed that apart from communist and formerly communist states, cold states are highly developed, and apart from oil rich states, hot states are less developed (Dell et al. 2012: 70). In addition, we note that states at high elevations have lower $\mu$ than similar ones at lower elevations, as exemplified by Lesotho, Bolivia, and Nepal. These

\footnotetext{
${ }^{39}$ The papers of Hall and Jones (1999), Acemoglu et al. (2001), and Rodrik et al. (2004) tautologically employ measures of formal institutions on the input side and development on the output side of their theory and modeling. Of course, robust statistical results, as those papers exhibit, can be expected when an acausal correlate of the output is included as an input.

${ }^{40} \mu$ is standardized by design. That is, it is zero-centered and its variance is 1 . By construction, $\mu$ is highly correlated with the log of per capita income $(r=0.95)$. Denoting the latter $\mathcal{E}, \Delta \mathcal{E}=1.142 \Delta \mu$. This relation is helpful when interpreting the impact of model parameters on income, however, it is strictly valid only in 2015, the year of the reported GNI data. We note further that our measure of development is formulated in a spirit very similar to the one that motivates the recent work of Leandro Prados de la Escosura, in which he introduces a measure of augmented human development (2021).
} 


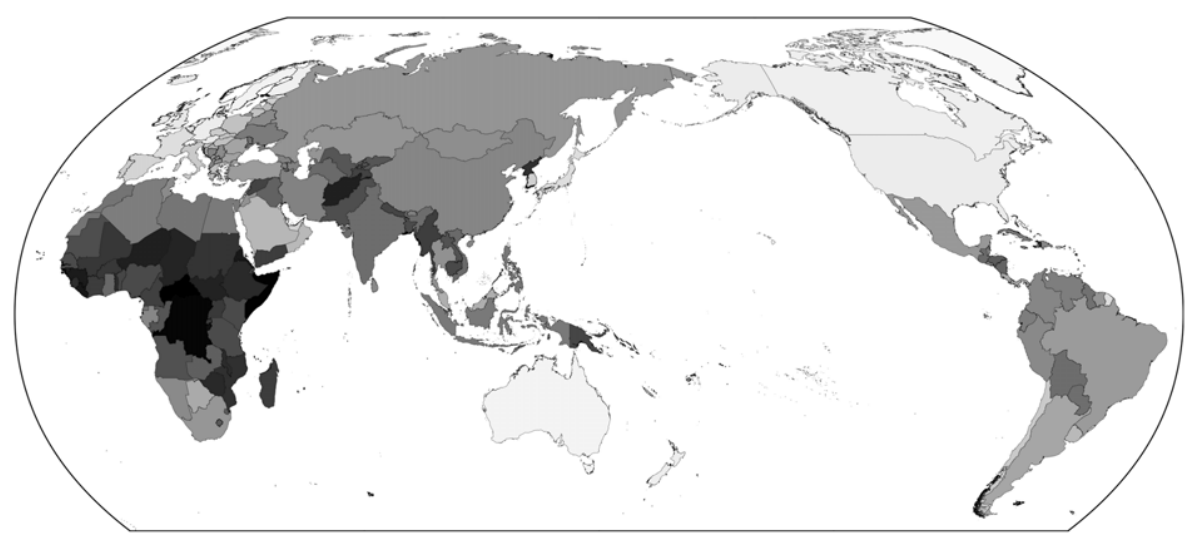

Map 3. The map of $\mu$ by nation. Note: The deepest grays correspond to the lowest states of development and white to the highest, or $\mu=\mp 2$ respectively.

observations suggest that some proxies for climate, geography, natural resources, and communist history are likely candidates for the $x_{i}{ }^{41}$ The same may be said, too, for gamos. From map 2, we see that its geospatial correlations are large, and if we compare maps 2 and 3, we see that those correlations are coincident; where gamos is high, $\mu$ is low. Each of these candidate sources is plausibly causative of development, ${ }^{42}$ and each conforms to the boundary condition imposed by persistence. ${ }^{43}$ For the purposes of this article, we restrict ourselves to $x_{i}$ drawn from these five categories. These are sufficient to achieve the article's mission, which is to assess the role of family in economic history. Other categories, whose impact is not obvious from the map and therefore are likely to be of secondary importance, for instance religion, civil and international conflict, imperial conquest, ethnic fractionalization, good and bad neighbor effects, and genetics, deserve consideration, too, though giving them their due is beyond the scope of this article.

For each of the five categories, we now describe the relevant proxies or candidate $x_{i}$. In the second century CE, Ptolemy deduced that global climate variation is driven by insolation that is modulated by the sun's varying inclination to Earth's spherical surface (Edwards 2011: 128). By his analysis, climate variation is nearly independent of latitude within a zone $16.5^{\circ}$ north and south of the equator, and nearly linear in

\footnotetext{
${ }^{41}$ The simplifying assumption of linearity in Eq. (1) precludes detection of optimal conditions such as one might anticipate for climate and natural resources. This assumption is easily amended, but we have found limited justification for doing so.

${ }^{42}$ We note that AJR say climate is spurious and that Rodrik says that NIE seeks to show that climate isn't important, while Aristotle, Ibn Khaldun, Montesquieu, Diamond, and Dell et al. have written persuasively to the contrary.

${ }^{43}$ Though the timescale of persistence tells us that the model must be dominated by sources that vary negligibly over a century, the model must also admit of enough source variation to account for the small decorrelation over that same period. Of the five sources or categories—climate, geography, family structure, natural resources, and communism - the first three are materially constant over centuries and the last two are modern and transient. The former are likely to account for most of the variance of $\mu$, and the latter are likely to contribute to its decorrelation.
} 


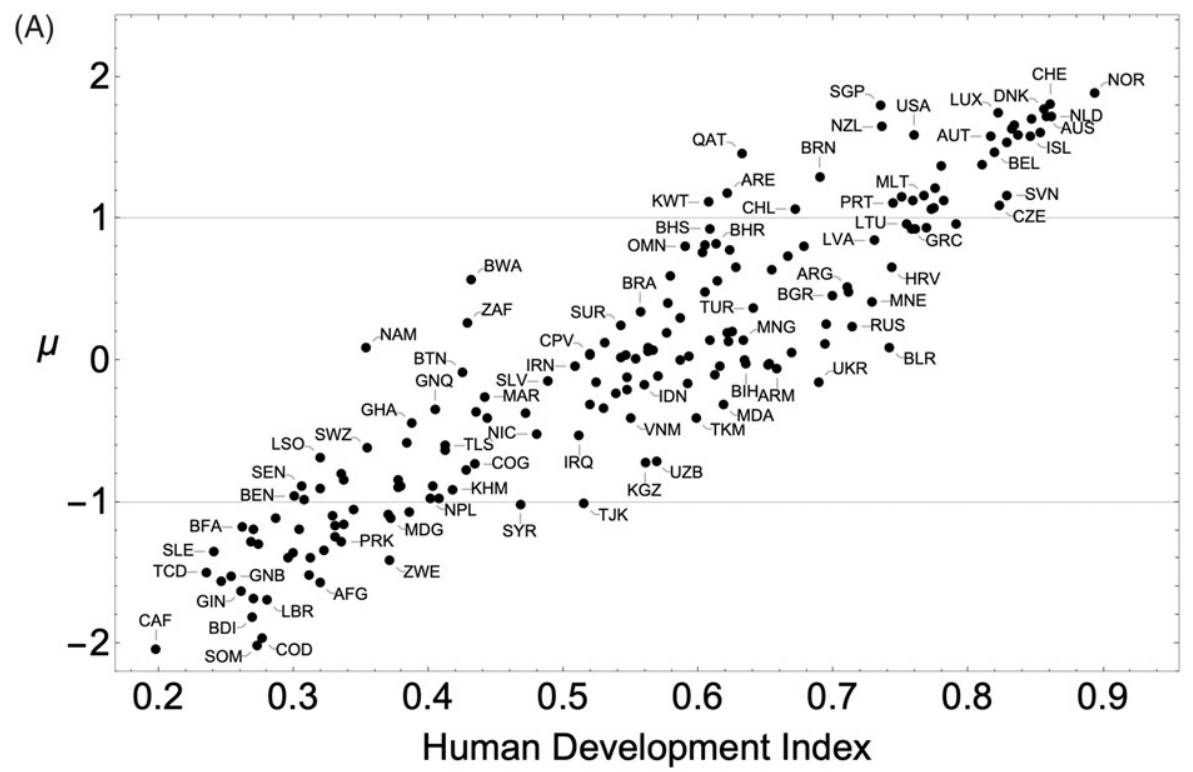

(B)

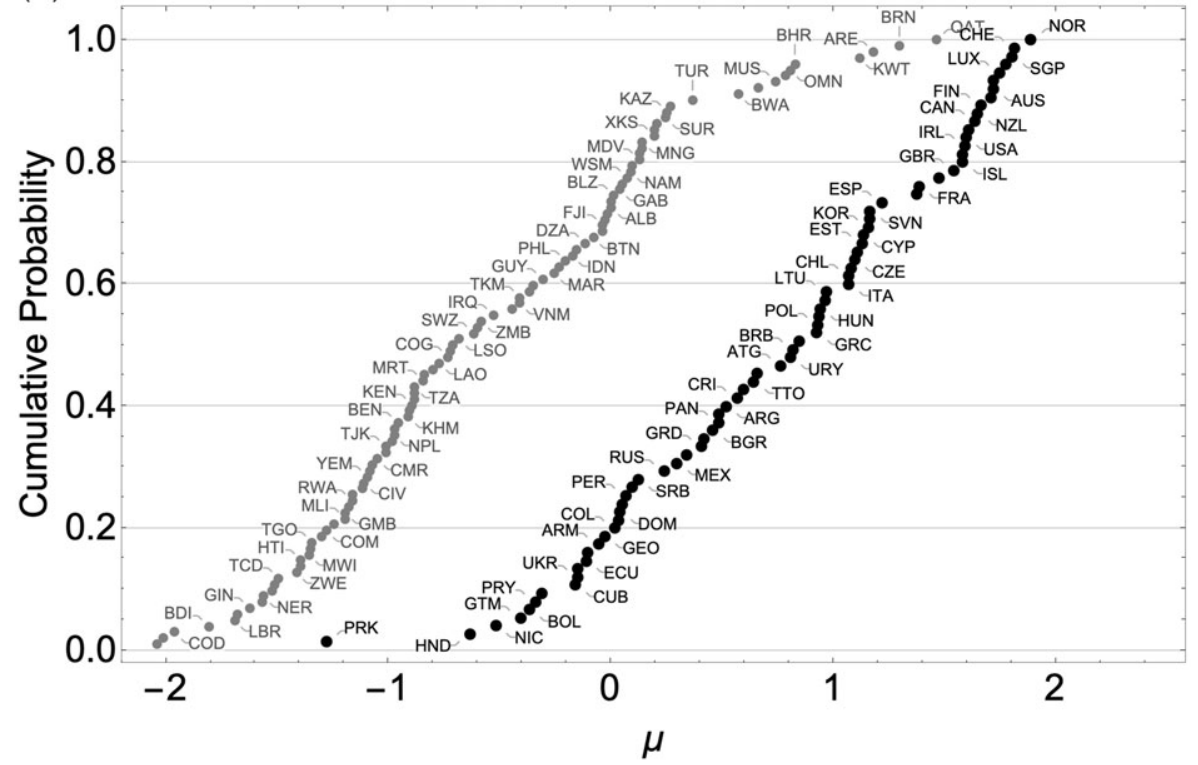

Figure 6. Two views of development, $\mu$. Notes: (A) The correspondence between HDI and $\mu(r=0.93)$. (B) The well-separated CDFs of $\mu$ in $\mathcal{P}$ (left/gray) and $n \mathcal{P}$ (right/black).

latitude in zones lying between $30^{\circ}$ and $50^{\circ}$ on either side of the equator. Edmond Halley, in 1686, and George Hadley, in 1735, theorized that convection would also bear heavily on near-equatorial climate, extending the range of latitude independence all the way to the lower subtropics, or roughly $\pm 30^{\circ}$ (Hartmann 
Table 3. Candidate proxies for sources of development across five categories

\begin{tabular}{ll}
\hline Category & Candidate Sources of Development \\
\hline Climate & $\begin{array}{l}\text { Distance from the equator; insolation (Rose 2020); mean monthly } \\
\text { high temperature (Climate Research Unit of East Anglia); potential } \\
\text { evapo-transpiration (Zomer et al. 2008); aridity (Zomer et al. 2008) }\end{array}$ \\
\hline Geography & Mean elevation; ruggedness (Nunn and Puga 2012) \\
\hline Natural Resources & $\begin{array}{l}\text { Natural resource revenue in excess of costs: Log per capita expressed in } \\
\text { US dollars (World Bank, Popular Indicators); as a fraction of GDP (World } \\
\text { Bank 2020a) }\end{array}$ \\
\hline Communism & Communist governance: yes/no; duration \\
\hline Family Structure & gamos; P/nP; sex ratio at puberty (CIA) \\
\hline
\end{tabular}

1994: 142). Climate's impact on the economy was noted by Aristotle, and has been elaborated on much since, but in a landmark paper, the Nobelist William Nordhaus remarks that by the mid-twentieth century, climate had all but disappeared from the economic development literature. A figure in that same paper suggests a weak linear dependence of log per capita GDP on distance from the equator, $\varphi$, for higher latitudes, and an independence of the two for lower latitudes. This, and his investigation of the role of temperature on income led him to conclude, "We should surely look to factors other than climate to explain most differences in the wealth and poverty of nations" (Nordhaus 1994: 356-64). Soon thereafter, in a paper on the deep roots of national productivity, Hall and Jones (1999) proxied climate as $\varphi$. For the more than four billion people who live within $30^{\circ}$ of the equator, $\varphi$ explains less than 5 percent of the variance of physical measures of climate, for instance temperature, aridity, and potential evapo-transpiration (PET). Overall, $\varphi$ is a poor proxy of climate, and one that no scientist since Ptolemy would endorse, but it is the economists' choice, ${ }^{44}$ so we include it here for completeness (see Table 3). Insolation is highly correlated with annual, national temperature where $\varphi>30^{\circ}(r=0.82)$, and moderately so where $\varphi<30^{\circ}(r=0.30)$, so it promises to be a moderately better proxy than $\varphi{ }^{45}$ Of the aforementioned physical measures of climate, PET is probably the least well known. It is highly correlated with temperature $(r=0.93)$, and it exhibits systematically negative deviations where the humidity is very high, and positive deviations where the humidity is very low.

As proxies for geography we use mean elevation and terrain ruggedness. We justify the former on the grounds that higher elevation goes hand in hand with more difficult living conditions by virtue of agriculture, weather, access, and the partial pressure of oxygen. Terrain ruggedness was introduced by Nunn and Puga (2012). We deploy that measure with its elevation component removed.

For climate and geography proxies, we use averages without weighting. Population-weighting is something to consider for future work, though our initial explorations hint at little merit in it. For natural resources, we rely on the World

\footnotetext{
${ }^{44}$ Acemoglu et al. (2001), Rodrik et al. (2004), and Schulz et al. (2019).

${ }^{45}$ Insolation outperforms $\varphi$ where $\varphi<30^{\circ}$ because insolation, like temperature, is independent of latitude near the equator, whereas the same cannot be said for $\varphi$.
} 
Bank's compilation of annual natural resources rents as a fraction of GDP, averaged over the years 2006 to 2015 . We use this in two forms; as reported and as the log of per capita rents in US dollars. For communism, our proxies focus on whether a nation did or did not have a Marxist-Leninist government. We employ a binary variant and one that is linear in its duration. For family structure, we use gamos, There are two choices for gamos, $g_{S}$ and $g$. As explained, $g_{S}$ is a measure of social convention that risks confounding by sources other than polygamy, and $g$ is a direct measure of polygamy. As additional proxies for family structure, we use the $\mathcal{P} / n \mathcal{P}$ binary and sex ratio at puberty. We have no evidence that sex ratios exhibit the longterm persistence demanded of a candidate source. Nevertheless, we include it here because the social conventions that arise from polygamy are occasionally present in high sex ratio societies.

From these 14 proxies, we construct 648 models of the form given in Eq. (1), where $n \leq 5$ and no model includes more than one candidate from each category. To select the best of them, we use the Bayes Information Criterion (BIC), a log likelihood estimate conjoined with a penalty for model complexity. BIC assesses the extent to which the data, usually called the evidence, favors the model, usually referred to as a scientific theory. We follow Kass and Raftery (1995) who teach that, when comparing two models, a BIC difference exceeding $6, \Delta \mathrm{BIC}>6$, is a strong indication that the evidence favors the model with the lower BIC. Being that BIC is logarithmic, the strength of that indication increases exponentially with $\triangle \mathrm{BIC}$. Accordingly, Kass and Raftery teach that $\triangle \mathrm{BIC}>10$ is a very strong indication that the evidence favors the model with the lower BIC. Though most researchers use the term model selection as a label for Kass and Raftery's protocol, that protocol is more easily understood as quantitative alternative hypothesis testing.

In addition to BIC, we examine the geospatial correlations of the model residuals. The geospatial correlations of development, evident in map 3, must arise, in large part if not in toto, from the geographic extent of its sources. Large, geospatially correlated residuals signal the omission of a variable of geospatial scope. We assay these with $I$ ', a logarithmic measure of geospatial correlations in the model residuals (Seligson and McCants 2021). Only if $I^{\prime}<I_{50}^{\prime}=-2.88$ is the model more likely than not to be free of omitted geospatially significant variable bias.

In figure 7 we represent each of the 648 models by its BIC and I', and we label many of them with their explained variance. Strung out like stars in the Milky Way, they form a band that runs from the upper right, where models have low explanatory power, high BIC, and considerable likelihood of suffering from omitted variable bias, to the lower left where they are better in every respect. The best model-the one with lowest $\mathrm{BIC}$ - is indicated by the large black pentagon which we call $\mathcal{M}_{5}$. It selects PET, mean elevation $(h)$, log per capita natural resources rents ( $n r r)$, the duration of communist rule $(\tau)$, and gamos $(g)$. The maximum $p$-value of $\mathcal{M}_{5}$ 's parameters is $1 \times 10^{-6}$, indicating that the model is well defined. Its BIC is 15 points lower than the closest competitor. By Kass and Raftery then, the data very, very strongly favor $\mathcal{M}_{5}$ over all others as a theory of development. Furthermore, its $I^{\prime}=-3.07<I_{50}^{\prime}=-2.88$, so we can have better than 50 percent confidence that, if we have omitted some variables, which we no doubt have, they do not produce large geospatial correlations among nations. Finally, the explained variance, an output of model selection rather than its criterion, is $R^{2}=0.77$. 


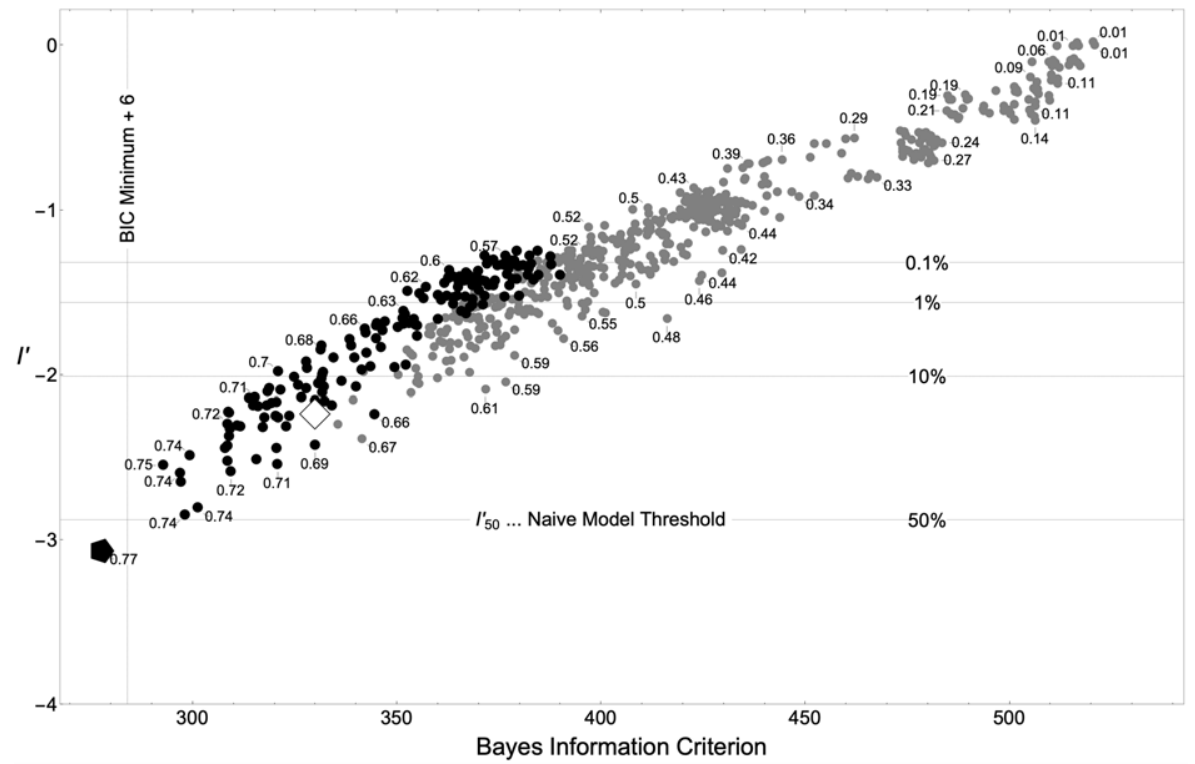

Figure 7. Five-parameter model selection. Notes: Each dot or polygon represents one of 648 different combinations of the 14 proxies. Black coloring signifies that $g$, the prevalence of male plural marriage, is one of the model variables. $\mathcal{M}_{5}$, the optimal five-parameter model, is represented by the five-sided polygon in the lower left corner. $\mathcal{M}_{4}$, the optimal four-parameter model (from which all measures of family structure are excluded), is represented by the four-sided polygon.

Let us now compare $\mathcal{M}_{5}$ to models without a family structure variable. The best of these, $\mathcal{M}_{4}$, is denoted in figure 7 by the white four-sided polygon at $\mathrm{BIC} \cong 580$. If $\triangle B I C>6$ implies strong and $\triangle B I C>10$ implies very strong, what adjective is appropriate for $\triangle \mathrm{BIC}=77$, the value pertinent to this comparison? Decisive. Apart from gamos, $\mathcal{M}_{4}$ deploys the same variables as $\mathcal{M}_{5}$. Simply put, $\mathcal{M}_{5}$ is incomparably superior to $\mathcal{M}_{4}$, and the superiority is due entirely to the inclusion of gamos. Thus we may fairly conclude, as we hypothesized, that the suite of social conventions born of polygamy, as proxied by its prevalence in 1900, is a powerful determinant of contemporary social and economic development.

Table 4 is a summary of key features of $\mathcal{M}_{5}$. An index $(i)$, the variable name $\left(x_{i}\right)$, its corresponding unit of measure, its standard deviation across the data set $\left(\sigma_{i}\right)$, and the OLS estimate of its corresponding parameter $\left(c_{i}\right)$ are in the first four columns. In the next column, following McCloskey's (2002) suggestive nomenclature, we use the term oomph for $2 \sigma_{i} c_{i}$, an expression of the overall contribution of an input, $x_{i}$, on the output $\mu$ (which, roughly speaking, spans the range \pm 2 ). The two variables with the greatest oomph are climate and polygamy, and communist governance is a near third. This overturns the astounding claims by Nordhaus (1994), Hall and Jones (1999), Acemoglu et al. (2002), and Rodrik et al. (2004) that climate and culture are insignificant contributors to long-term economic development. We must note, though, that $\mathcal{M}_{5}$ is by no means the last word. More complex models, and 
Table 4. $\mathcal{M}_{5}$ parameter summary table

\begin{tabular}{clccccc}
\hline$i$ & $x_{i}$ & units & $i$ & $c_{i}$ & oomph & p-value \\
\hline 1 & PET & ${ }^{\circ} \mathrm{C}$ & 9.31 & -0.059 & 1.09 & $2.7 \times 10^{-19}$ \\
\hline 2 & Elevation & $100 \mathrm{~m}$ & 5.24 & -0.036 & 0.38 & $1.3 \times 10^{-06}$ \\
\hline 3 & Resources & $\log$ & 2.16 & 0.108 & 0.47 & $3.7 \times 10^{-09}$ \\
\hline 4 & Communism & decade & 2.44 & -0.144 & 0.70 & $5.0 \times 10^{-14}$ \\
\hline 5 & gamos & $\%$ & 7.79 & -0.062 & 0.97 & $4.9 \times 10^{-19}$ \\
\hline
\end{tabular}

Note: Column labels are described in the text.

models incorporating variables we did not consider here may change the rank ordering of oomph, but, surely, we must expect that climate and family structure will be on the shortlist of major contributors to the wealth and poverty of nations.

In this penultimate paragraph, we make a few comparisons of our model with others, and we note a few of its unique features. From the fact noted in a footnote ${ }^{40}$, $\Delta \mathcal{E}=\Delta \log (\mathrm{GNI}) \cong 1.142 \Delta \mu$, we may infer the sensitivity of income to any one of the input variables. For climate, we get -6.5 percent per ${ }^{\circ} \mathrm{C}$. The value obtained by Dell et al. (2009) for GDP is -8.5 percent per ${ }^{\circ} \mathrm{C}$. We attribute the difference to unaccounted-for omitted variable bias in their univariate model, differences between dollar-denominated GDP and GNI denominated by purchasing power parity, and some other methodological differences. Next, the inferred sensitivity of GNI to polygamy is -6.9 percent per 1 percent change in prevalence. In practice, the prevalence in the $\mathcal{P}$-states is rarely less than 6.7 percent, and the mean prevalence for all $\mathcal{P}$-states is 13.3 percent. These prevalences correspond to a GNI suppression (relative to $n \mathcal{P}$-states where the prevalence is zero) of 38 percent and 61 percent, respectively. These values are consistent with Tertilt's estimates, though our methods are rather different (Tertilt 2005: 1343). Lastly, map 3 tells us that communism has a large (negative) bearing on $\mu$. This led us to include proxies for communist governance in the model selection process. We did not, however, specify the sign of communism's effect, and model selection might well have rejected communism altogether. But it did not; the best model without a communist governance proxy is $54 \mathrm{BIC}$ points greater than that of $\mathcal{M}_{5}$. This multivariate model of materially all nations on the planet tells us that the inferred cost or burden of communist governance on income is 15 percent per decade.

Clearly, as natural philosophers have been arguing for at least two millennia, climate matters for development; and clearly, as historians have been arguing for at least three, history matters too. Our framework permits us to assess their relative importance, but we can only weigh what we have included. In the hands of others, this same framework may reveal that beyond family and beyond communist ideology, there are other aspects of history that matter, too.

\section{Conclusion}

We began this article by asking the question "where is the family in economic history?" We conclude it by arguing that it should be squarely at the center. 
Work in economic sociology as well as in economic history has demonstrated time and again that social convention matters to economic outcomes. This insight is often shorthanded (imprecisely as we argue elsewhere) as "institutions matter." We agree that they do, but which ones in particular, and in what ways? We show here that family law and practice, specifically the dichotomy between monogamy and polygamy, generates a bimodal set of linked conventions governing interactions between individuals, households, the state and marketplace, and of course, between the sexes. We identify a set of polygamy-born conventions that typically occur together, a suite we call gamos. It is associated with the commodification of women at the expense of their health, wealth, education, and personal agency. It is also associated with high birth rates, harsh justice, and authoritarian rule. If family law or practice shapes the conventions in which all economic activity is embedded, then we must expect gamos to matter for economic outcomes. That marriage law has not been invoked in standard models of economic development or inequality strikes us as a hobbling omission. Our work develops two independent measures of gamos for 177 nations $-g_{S}$, based on the suite of 11 salient social conventions that we attribute in part to polygamy, and $g$, based on estimates of the prevalence of polygamy in 1900 - and finds them highly correlated $(r=0.83)$. In a causal, multivariate, and compact model of long-term social and economic development, we deploy $g$-alongside variables describing climate, geography, communism, and natural resources-to find that its contribution is second only to climate's, a factor long recognized as important, even if it has fallen out of favor with economists. The family, however, has been conspicuously absent from cross-sectional economic development modeling that, to paraphrase North, has not produced satisfactory explanations despite 70 years of immense effort (1990: 11). When ubiquity stares us in the face, we often fail to notice. The findings reported on here remind us that we ignore the family at our peril.

Supplementary material. To view supplementary material for this article, please visit https://doi.org/10. $1017 /$ ssh.2021.23

Acknowledgments. The authors are grateful for the opportunity to discuss aspects our research with Robert Paul, Francis Fukuyama, John Donohue, Rose McDermott, Mathieu Arnoux, Thomas Martin, Walter Scheidel, Jane Humphries, Deborah Oxley, Judy Stephenson, Harriett Zurndorfer, and Lauren Gage Segal. We also thank Fabian Drixler for his extensive comments on an early version of the paper. Finally, we thank the organizers of economic history workshops at Northwestern, Oxford, the Paris School of Economics, and Yale, for the opportunity to present aspects of the work in progress, as well as the thoughtful comments received after an SSHA presentation in Phoenix (2019).

\section{References}

Abramitzky, Ran, Adeline Delavande, and Luis Vasconcelos (2011) "Marrying up: The role of sex ratio in assortative matching.” American Economic Journal: Applied Economics 3 (3): 124-57.

Abu Rabia, Rawia (2011) "Redefining polygamy among the Palestinian Bedouins in Israel: Colonialism, patriarchy, and resistance." American University Journal of Gender Social Policy and Law 19 (2): 459-93.

Acemoglu, D., S. Johnson, and J. A. Robinson (2001) “The colonial origins of comparative development: An empirical investigation.” The American Economic Review 91 (5): 1369-1401.

- (2002) "Reversal of fortune: Geography and institutions in the making of the modern world income distribution.” The Quarterly Journal of Economics 117 (4): 1231-94. 
Ahmadu, Fuambai Sia (2016) "Female circumcision—women must have the right to choose." Sierra Leone Telegraph, February 8.

Al-Krenawi, Alean (2014) Psychosocial Impact of Polygamy in the Middle East. Springer.

Amnesty International (2012) www.amnesty.org (accessed June 3, 2019).

Arbuthnot, John (1710) "An argument for divine providence, taken from the constant regularity observed in the births of both sexes." Philosophical Transactions of the Royal Society (27): 186-90.

Armstrong, Karen (1993) Muhammad: A Biography of the Prophet. Harper Collins.

Becker, Gary (1973) "A theory of marriage: Part I." Journal of Political Economy 81 (4): 813-46.

- (1981) A Treatise on the Family. Harvard University Press.

Belmaker, R. H. (2012) "Successful cultural change: The example of female circumcision among Israeli Bedouins and Israeli Jews from Ethiopia." Israeli Journal of Psychiatry 49 (3): 178-83.

Betzig, Laura (1986) Despotism and Differential Reproduction: A Darwinian View of History. Aldine Publishing Company.

Botticini, Maristela, and Aloysius Siow (2003) "Why dowries?" American Economic Review 93 (4): 1385-98.

Brass, William, Ansely J. Coale, Paul Demeny, Don F. Heisel, Frank Lorimer, Anatole Romaniuk, and Etienne van de Walle (1968) The Demography of Tropical Africa. Princeton University Press.

Carmichael, Sarah G., Alexandra de Pleijt, Jan Luiten van Zanden, and Tine De Moor (2016) "The European marriage pattern and its measurement." Journal of Economic History 76 (1): 196-204.

Chagnon, Napoleon A., Robert F. Lynch, Mary K. Shenk, Raymond Hames, and Mark V. Flinn (2017) "Cross-cousin marriage among the Yanomamo." Proceedings of the National Academy of Sciences 114 (13): E2590-E2607, doi: 10.1073/pnas.1618655114.

Chamie, J. (1986) "Polygyny among Arabs." Population Studies 40 (1): 55-66.

Dagum, Camilo (1980) "Inequality measures between income distributions with applications." Econometrica 48 (7): 1791-1803.

Dayal, John (2001) "Lies, half truths and statistics: The fine art of demonization as political demography." Center for Policy Studies, http://www.cpsindia.org/index.php/pub/87-religious-demography-of-india/ reviews/84-indian-currents-lies-half-truths-and-statistics-by-john-dayal (accessed June 28, 2019).

de la Escosura, Leandro Prados (2021) "Inequality beyond GDP: A long view." Instituto Figuerola Working Papers in Economic History. ISSN: 2341-2542.

Dell, Melissa, Benjamin F. Jones, and Benjamin A. Olken (2012) "Temperature Shocks and Economic Growth:Evidence from the Last Half Century." American Economic Journal: Macroeconomics 4 (3): 66-95.

De Moor, Tina, and Jan Luiten van Zanden (2010) "Girl power: The European marriage pattern and labour markets in the North Sea Region in the late medieval and early modern period." Economic History Review 63 (1): 1-33.

Dell, Melissa, Benjamin F. Jones, and Benjamin A. Olken (2009) "Temperature and income: Reconciling new cross-sectional and panel estimates." American Economic Review 99 (2): 198-204.

Dennison, Tracy, and Sheilagh Ogilvie (2014) "Does the European marriage pattern explain economic growth?” Journal of Economic History 74 (3): 651-93.

Doniger, Wendy (2009) The Hindus. Penguin Books.

Donohue, John J. (2017) "Comey, Trump, and the puzzling pattern of crime in 2015 and beyond." Columbia Law Review 117 (5): 1297-1354.

Edwards, Paul N. (2011) "History of climate modeling." WIRES: Climate Change 2 (1): 128-39.

Edwards, Walter F. (1982) "A description and interpretation of the Kwe-Kwe tradition in Guyana." Folklore 93 (2): 181-92.

Elbedour, Salman, Anthony J. Onwuegbuzie, Corin Caridine, and Hasan Abu-Saad (2002) "The effect of polygamous marital structure on behavioral, emotional, and academic adjustment in children: A comprehensive review of the literature." Clinical Child and Family Psychology Review 5 (4): 255-71.

Elvin, Mark (1973) The Pattern of the Chinese Past. Stanford University Press.

Farrington, David P. (1986) "Age and crime." Crime and Justice 7: 189-250.

Fenske, James (2015) "African polygamy: Past and present." Journal of Political Economy 117 (C): 58-73.

Freedom House (2016) Freedom in the World 2016: The Annual Survey of Political Rights and Civil Liberties, https://freedomhouse.org/ (accessed August 8, 2019).

Freud, Sigmund (1950 [1913]) Totem and Taboo. Trans. James Strachey. W. W. Norton \& Company. 
Garcia-Moreno, Claudia, Alessandra Guedes and Wendy Knerr (2012) "Femicide." WHO/RHR/12.38 World Health Organization, https://apps.who.int/iris/bitstream/handle/10665/77421/WHO_RHR_12. 38_eng.pdf (accessed April 20, 2021).

Glowacki, Luke, and Richard Wrangham (2015) "Warfare and reproductive success in a tribal population." Proceedings of the National Academy of Science 112 (2): 348-53.

Golden, Paul Rakita (2002) The Culture of Sex in Ancient China. University of Hawaii Press.

Granovetter, Mark (1985) "Economic action and social structure: The problem of embeddedness." American Journal of Sociology 91 (3): 481-510.

Gruber, Siegfried (2002) "Regional variation in marriage patterns in Albania at the beginning of the 20th century." Paper presented at the Social Science History Association, St. Louis, MO, November 16.

Hagerty, Barbara (2008) "Philly's black Muslims increasingly turn to polygamy." All Things Considered, Transcript of National Public Radio, May 28.

Hajnal, John (1965) "European marriage patterns in perspective," in David Glass and D. E. C. Eversley (eds.) Population in History: Essays in Historical Demography. Aldine: 101-43.

Hall, R. E., and C. Jones (1999) "Why do some countries produce so much more output per worker than others?" Quarterly Journal of Economics 114 (1): 83-116.

Hartman, Mary S. (2004) The Household and the Making of History: A Subversive View of the Western Past. Cambridge University Press.

Hartmann, Dennis L. (1994) Global Physical Climatology. Elsevier.

Hartung, John (1982) "Polygyny and inheritance of wealth [and comments and replies]." Current Anthropology 23 (1): 1-12.

Hedström, P., and R. Swedberg (1996) "Social mechanisms." Acta Sociologica 39 (3): 281-308.

Hrdy, Sarah (1999) Mother Nature: A History of Mothers, Infants and Natural Selection. New York: Pantheon.

Hudson, Valerie (2016) Bride price/Dowry Scale 1. WomanStats Project Database, http://www.womanstats. org (accessed July 2, 2019).

Hudson, Valerie, and Andrea den Boer (2005) Bare Branches: The Security Implications of Asia's Surplus Male Population. MIT Press.

Hughes, Diane Owen (1978) "From bride price to dowry in Mediterranean Europe." Journal of Family History 3 (3): 262-96.

Inglehart, Ronald, and Christian Welzel (2017) "Cultural map," http://www.worldvaluessurvey.org/ images/Culture_Map_2017_conclusive.png (accessed May 24, 2020).

Kass, R. E., and A. E. Raftery (1995) "Bayes factors." Journal of the American Statistical Association 90 (430): 773-95.

Kornai, Janos (1980) Economics of Shortage. North-Holland Publishing Company.

Lape, S. (2002) "Solon and the institution of the 'democratic' family form." The Classical Journal 98 (2): $117-39$.

Lee, James, and Feng Wang (2001) One Quarter of Humanity: Malthusian Mythology and Chinese Realities, 1700-2000. Harvard University Press.

Lewis, David (1969) Convention: A Philosophical Study. Harvard University Press.

Luker, Vicki (2015) "Chiefly polygamy in Fiji during the 1840s and 1850s: A political and economic imperative?" Slides presented at the Department of Pacific and Asian History Seminar Series, Australian National University, March 3.

McCloskey, Deirdre N. (2002) “Three books of oomph." Eastern Economic Journal 27 (1): 115-118.

(2016) "Max U versus Humanomics: A critique of neo-institutionalism." Journal of Institutional Economics 12 (1): 1-27.

McDermott, Rose (2007) McDermott Female Circumcision Prevalence Scale. WomanStats Project Database, http://www.womanstats.org (accessed July 2, 2019).

— (2010) McDermott Polygyny Scale. WomanStats Project Database, http://www.womanstats.org (accessed July 2, 2019).

- (2018) The Evils of Polygyny: Evidence of Its Harm to Women, Men, and Society (The Easton Lectures). Cornell University Press.

Merton, Robert K. (1967) “On sociological theories of the middle range," in Robert K. Merton (ed.) On Theoretical Sociology. The Free Press: 39-72. 
Montesquieu (2008 [1721]) Persian Letters: A New Translation, trans. Margaret Mauldon. Oxford University Press.

Nordhaus, William (1994) "Climate and economic development: Climates past and climate change future." Proceedings of the World Bank Annual Conference on Development Economics, 1993.

North, Douglass C. (1990) Institutions, Institutional Change and Economic Performance. Cambridge University Press.

(1991) “Institutions." Journal of Economic Perspectives 5 (1): 97-112.

(1993) "Economic performance through time." Lecture to the memory of Alfred Nobel, http://www. nobelprize.org (accessed April 20, 2021).

Nunn, Nathan, and Diego Puga (2012) "Ruggedness: The blessing of bad geography in Africa." The Review of Economics and Statistics 94 (1): 20-36.

Orchid Project (2020) www.orchidproject.org (accessed December 28, 2020).

Osborn, Alan (1996) "Cattle, co-wives, children, and calabashes." Journal of Anthropological Archaeology 15 (2): 107-36.

Pearl, Judea, and Dana Mackenzie (2018) The Book of Why. Basic Books.

Pearsall, Sarah M. S. (2019) Polygamy: An Early American History. Yale University Press.

Perel, Esther (2006) Mating in Captivity. Harper Collins.

Plavcan, J. Michael (2012) "Body size, size variation, and sexual size dimorphism in early homo." Current Anthropology 53 (S6): S409-S423.

Polo, Marco (1958) The Travels. Trans. Ronald Latham. Penguin Classics.

Raffield, Ben, Neil Price, and Mark Collard (2017) "Male-biased operational sex ratios and the Viking phenomenon: An evolutionary anthropological perspective on Late Iron Age Scandinavian raiding." Evolution and Human Behavior 38 (3): 315-24.

Rodrik, D., A. Subramanian, and F. Trebbi (2004) "Institutions rule: The primacy of institutions over geography and integration in economic development." Journal of Economic Growth 9 (2): 131-65.

Rosário, Carmeliza (2008) "Desperate co-wives: The illegality of polygamy in the new Mozambican family law." MP Thesis, University of Bergen.

Rose, Brian E. J. (2020) "Insolation, the climate laboratory," https://brian-rose.github.io/Climate LaboratoryBook/courseware/insolation.html (accessed November 9).

Roser, Max (2020) "Fertility rate," https://ourworldindata.org/fertility-rate (accessed May 22).

Sampson, Robert J., John H. Laub, and Christopher Wimer (2006) "Does marriage reduce crime? A counterfactual approach to within-individual causal effects." Criminology 44 (3): 465-508.

Scheidel, Walter (2009) "Monogamy and polygyny." Princeton/Stanford Working Papers in Classics, http://www.princeton.edu/ ${ }^{2}$ pswpc/pdfs/scheidel/010903.pdf (accessed April 20, 2021).

Schulz, Jonathan F., Jonathan P. Beauchamp, and Joseph Henrich (2019) "The church, intensive kinship, and global psychological variation." Science 366 (6466), doi: 10.1126/science.aau5141.

Seligson, Daniel and Anne E. C. McCants (2021) "Co-evolving institutions and the paradox of informal constraints.” Journal of Institutional Economics, doi: 10.1017/S1744137420000600.

Sen, Amartya (2000) Development as Freedom. Anchor.

Solow, Robert (1985) "Economic history and economics." American Economic Review 75 (2): 328-31.

Tertilt, Michele (2005) "Polygyny, fertility, and savings." Journal of Political Economy 113 (6): 1341-71.

Tetrault-Farber, Gabrielle (2015) "Chechen official's call to legalize polygamy stirs social debate." The Moscow Times, May 19.

The Economist (2016) "Democracy index: Revenge of the 'deplorables." A report by The Economist Intelligence Unit, https://www.eiu.com/topic/democracy-index (accessed August 8, 2019).

Tignor, Robert (1972) "The Maasai warriors: Pattern maintenance and violence in colonial Kenya." The Journal of African History 13 (2): 271-90.

Todd, Emmanuel (1985) The Explanation of Ideology: Family Structure and Social Systems. Basil Blackwell.

Trevithick, Alan (1997) “On a panhuman preference for monandry: Is polyandry an exception?" Journal of Comparative Family Studies 28 (3): 154-81.

UNICEF (2014) "Guyana: Multiple indicator cluster survey," https://microdata.worldbank.org/index.php/ catalog/2731 (accessed May 24, 2020).

(2016) "UNICEF's work on FGM/C," www.unicef/org/media/files (accessed July 2, 2019).

Unisa, Sayeed, and Grace Bahalen Mundu (2011) "Bigamy in India: Finding from National Family Health Survey." International Institute for Population Sciences. 
Williamson, Oliver (2000) "The new institutional economics: Taking stock, looking ahead." Journal of Economic Literature 38 (3): 595-613.

Witte, John Jr. (2015) The Western Case for Monogamy over Polygamy. Cambridge University Press.

Womanstats (2020) "Physical security of women." WomanStats Project Database, http://www.womanstats.org (accessed July 2, 2019).

World Bank (2018) Worldwide Governance Indicators, https://info.worldbank.org/governance/wgi/ (accessed November 20, 2020).

- (2020a) Natural Resource Rents, https://data.worldbank.org/indicator/NY.GDP.TOTL.RT.ZS (accessed November 20, 2020).

(2020b) Popular Indicators, https://databank.worldbank.org (accessed November 20, 2020).

Zomer, R. J., A. Trabucco, D. A. Bossio, O. van Straaten, and L. V. Verchot (2008) "Climate change mitigation: A spatial analysis of global land suitability for clean development mechanism afforestation and reforestation." Agriculture, Ecosystems and Environment 126 (1/2): 67-80.

Zurndorfer, Harriett (2016) "Polygamy and masculinity in China: Past and present," in Kam Louie (ed.) Changing Chinese Masculinities: From Imperial Pillars of State to Global Real Men. Hong Kong University Press: 13-33.

Daniel Seligson is an independent scholar whose training is in physics (PhD, Berkeley 1983) and whose work experience (1984-2012) is in semiconductors, bioengineering, general management, and venture capital. He has been awarded eight US patents and one more is pending. Since 2015, he has focused his attention on nature, culture, and development.

Anne McCants is the Ann F. Friedlander Professor of Economic History at MIT, where she also directs the Concourse Program for first-year students. She serves as the president of the International Economic History Association and as coeditor of Social Science History and the Journal of Interdisciplinary History.

Cite this article: Seligson, Daniel and Anne E. C. McCants (2022) "Polygamy, the Commodification of Women, and Underdevelopment," Social Science History 46:1-34. doi:10.1017/ssh.2021.23 